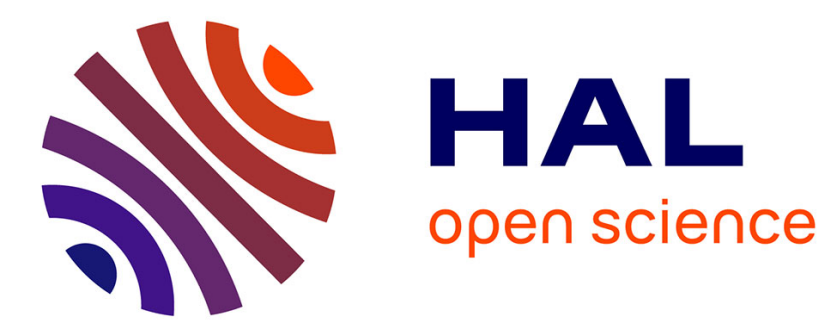

\title{
La chevalerie urbaine en Occitanie (fin Xe - début XIIIe siècle)
}

Martin Aurell

\section{To cite this version:}

Martin Aurell. La chevalerie urbaine en Occitanie (fin Xe - début XIIIe siècle). XXXIVe Congrès de la S.H.M.E.S., May 1996, Rome, Italie. pp.71-118, 10.3406/shmes.1196.1693 . halshs-00753411

\section{HAL Id: halshs-00753411 https://shs.hal.science/halshs-00753411}

Submitted on 22 Apr 2016

HAL is a multi-disciplinary open access archive for the deposit and dissemination of scientific research documents, whether they are published or not. The documents may come from teaching and research institutions in France or abroad, or from public or private research centers.
L'archive ouverte pluridisciplinaire HAL, est destinée au dépôt et à la diffusion de documents scientifiques de niveau recherche, publiés ou non, émanant des établissements d'enseignement et de recherche français ou étrangers, des laboratoires publics ou privés. 


\section{La chevalerie urbaine en Occitanie (fin Xe-début XIIle siècle)}

Monsieur Martin Aurell

\section{Citer ce document / Cite this document :}

Aurell Martin. La chevalerie urbaine en Occitanie (fin Xe-début XIIle siècle). In: Actes des congrès de la Société des historiens médiévistes de l'enseignement supérieur public, $27^{\mathrm{e}}$ congrès, Rome, 1996. Les élites urbaines au Moyen Âge. pp. 71-118.

doi : 10.3406/shmes.1996.1693

http://www.persee.fr/doc/shmes_1261-9078_1997_act_27_1_1693

Document généré le 20/10/2015 


\title{
LA CHEVALERIE URBAINE EN OCCITANIE (FIN Xe - DÉBUT XIIe SIÈCLE)
}

\begin{abstract}
« Cette ville fortifiee a huit portiers, chacun d'entre eux disposant de mille chevaliers pour garder ses huit portes. Quand on leur fait la guerre, ils y sont tous ensemble, et ils ont résisté ainsi longtemps. Chacun de ces chevaliers s'y connan̂t en amour et croit aimer la meilleure. C'est pourquoi ils sont tous preux, vaillants, éduques, avenants... Ce sont des chevaliers merveilleux. Car par amour, l'homme devient plus preux, plus joyeux et plus large " 1 .
\end{abstract}

Son errance mène Jaufre, le héros du seul roman arthurien rédigé en langue d'oc, à Montbrun 2. Huit mille chevaliers (cavalier) gardent cette cite, que gouverne Brunissen, la dame qu'il épousera un jour. Sous la plume de l'auteur ano-

1. E el castel a.VIII. porters / qe cascus a .M. cavaliers / qe garon.VIII. porte qe.i a. E can nul hom guera lur fa / qui meseix sun totz ensems / e aixi an tengut lonc tems. / E cascun enten en amor / E cuja amar la melor. / Per so sun tuit pros e valent / e enseinat e avinent. / $E$ cavaliers meravilos. / Car per amor es om pus pros, / pus gais e de major largesa, Jaufre, ed. R. Nelli, R. Lavaud, Les troubadours, Paris, 1960, p. 200, v. 3093-3115. Nous avons traduit castel par \& ville fortifiee \#, conformément à une acception admise par le dictionnaire de l'ancien provençal d'E. Levy, plutôt que par * château *, eu égard au nombre très élevé de guerriers qui habitent dans cette forteresse.

2. Le nom de cette ville fictive a peut-être été emprunté à un village proche de Narbonne, en Bas-Languedoc, où Jauffe a été écrit, si ce n'est en Catalogne. Un Peire Raimond de Montbrun, miles ou chevalier, figure parmi les consuls de Narbonne au XIIIe siècle, R. W. Emery, Heresy and Inquisition in Narbonne, New York, 1941, p. 28. Sur les circonstances de la redaction de Jaufre, cf. M. de Riquer, « Los problemas del roman provenzal de Jaufre », dans Melanges $C$. Brunel, Paris, 1955, t. 2, p. 435-461. Une datation tardive, d'environ 1225, est proposee par B. Schmolke-Hasselmann, * Der arthurische Versroman, von Chretien bis Froissart : zur Geschichte einer Gattung », Zeitschrift fur Romanische Philologie, 177 (1979), p. 18. 
nyme écrivant à la fin du XIIe siècle en honneur du roi d'Aragon, le genre de vie et les qualités de ces combattants urbains prennent une tournure bien idéalisée, idyllique même : ces hommes sont aussi vaillants que courtois, aussi aptes à la guerre qu'à l'amour. Ici, la fiction littéraire traduit l'image que l'aristocratie militaire des villes occitanes forge d'elle même. Ce texte témoigne de la forte identité d'un groupe social, fier d'appartenir à l'élite des armes et de la fortune qui tient entre ses mains les destinées de sa cité.

La chevalerie urbaine se définit comme l'ensemble des guerriers préposés à la defense des villes et de leur « district » (districtus), le pays environnant où ils exercent leur pouvoir de contrainte. Les luttes entre les comtes et les châtelains, relayées par le conflit entre Toulouse et Barcelone, promeuvent ces spécialistes de la guerre à un rang privilégié dans la société méridionale des XIe et XIIe siècles. Ins sont omniprésents dans les sources. Les chartes des fonds épiscopaux, capitulaires et monastiques les mentionnent souvent. Il en va de même avec les actes des comtes, vicomtes et seigneurs des villes ou avec les cartulaires municipaux constitués au XIIIe siècle. Or, au cours des dernières décennies, de nombreuses monographies urbaines ont exploite ces documents pour constater le rôle de premier plan que jouent les guerriers citadins dans le pourtour occidental de la Méditerranée 3.

A l'aide de ces travaux récents, il est aisé de replacer cette catégorie sociale dans un contexte historique et géographique précis. D'une part, le cadre chronologique choisi couvre une période où les principautés occitanes jouissent d'une large autonomie à l'égard du pouvoir royal : entre l'effondrement de l'Empire carolingien et la croisade albigeoise, l'émergence de comtés, vicomtés et seigneuries indépendantes accentue la spécificité de ces territoires. D'autre part, notre espace concerne la Catalogne, le Languedoc, le Rouergue et la Provence, régions partageant un nombre considérable de traits communs (figure 1). Domi nés par les comtes de Barcelone et de Toulouse et, à un degré moindre, par les vicomtes de la maison de Trencavel, ces pays méditerranéens, dans lesquels on parle les dialectes d'oc, ne sauraient être confondus avec l'Aquitaine, placée sous l'emprise des Plantagenêt et ouverte à l'Atlantique.

En comparaison de l'Italie du nord, ils se caractérisent par la période tardive de leur essor commercial. Ce n'est, en effet, qu'autour de 1150 que les hommes les plus entreprenants des ports catalans, languedociens et provençaux construi -

3. « L'importance de la chevalerie urbaine est un trait distinctif des pays languedociens. », P. Wolff, Histoire de Languedoc, Toulouse, 1967, p. 159-160. Il n'existe pas d'ouvrage consacré exclusivement à cette catégorie sociale. Mais les études sur les villes et les principautés occitanes, que nous citerons au fil de cet exposé, lui consacrent de nombreux passages. 
sent quelques nefs et participent aux échanges à long cours 4 ; ils degagent, à cette date, les activites économiques de leur ville de la forte emprise des marchands génois et pisans qui ont longtemps accaparé le commerce en Méditerrané occidentale 5. En attendant cette émergence tardive d'une bourgeoisie autochtone, dont les affaires mercantiles et financières sont l'occupation principale, la voie est libre pour les milites qui contrôlent aisément le pouvoir municipal. Avant le XIIIe siecle, la ville occitane est davantage restée citadelle que marche ; les guerriers en ont longtemps été les maîtres.

\section{Un groupe voué à la guerre}

L'Empire romain lègue un réseau serré de civitates à nos régions. A la veille de l'an mil, ces villes apparaissent, cependant, de dimensions bien rétrécies par rapport au IIe siècle. A Arles ou à Nîmes, la vie s'est recroquevillée autour des Arènes et d'un mince tronçon de l'ancienne enceinte romaine 6. A Marseille, l'habitat s'est concentre sur la butte Saint-Laurent autour du castrum Babonis ?. A Nice, l'ancien site de plaine de Cimiez est abandonné au profit du Puy du Chateau : en 1217, cette ville apparaît à un croise qui la contemple de son bateau comme un « castrum construit sur une haute montagne » 8 . C'est, en effet, sur des buttes et collines que l'on perche les cités crées de toutes pieces a

4. * L'essor véritable, le moment du grand dégel maritime et routier, ne se situe pas dans cette région avant 1150 », G. Duby, * Les villes du Sud-Est de la Gaule du VIIe au XIe siècle *, Hommes et structures du Moyen Âge, Paris, Mouton, 1973, p. 117. L'apparition, seulement vers 1140, de nefs de particuliers à Barcelone, permettant le démarrage du commerce lointain et l'abandon d'une Economie fondée sur les tributs musulmans et sur le marché local, est l'un des éléments principaux du modele de S. Bensch, Barcelona and its rulers, 1096-1291, Cambridge, University Press, 1995, p. 4, 116-117 et 168. Même chronologie pour la Provence, en ce qui concerne la liaison entre la production locale et le commerce a long cours; les tarifs de tonlieu d'Arles connaissent une augmentation brutale à partir de 1144, J.-P. Poly, La Provence et la société féodale (879-1166), Paris, Bordas, 1976, p. 231 et 247-249. Pour Toulouse, la première mention de navigation sur la Garonne date de 1120, J. H. Mundy, Liberty and Political Power in Toulouse, 1050-1230, New York, 1954, p. 262.

5. Sur le rôle passif du littoral languedocien dans le commerce au début du XIe siècle : * Montpellier, comme Narbonne, ne peuvent s'extérioriser que par l'intermédiaire des cités italiennes. Leur vie commerciale reste sous la dépendance de l'étranger et l'exploitation de la mer est fonction le plus souvent des initiatives pisanes ou génoises. „, A. Dupont, Les cités de la Narbonnaise premiere depuis les invasions germaniques jusqu'd l'apparition du consulat, Nîmes, 1942, p. 619.

6. P. Martel, * L'époque médiévale *, dans Histoire de Nûmes, Aix, Edisud, 1982, p. 110.

7. Pour la topographie des villes provençales, cf. P.-A. Février, Le développement urbain en Provence de l'époque romaine d la fin du XIV' sizcle, Paris, 1964.

8. Ad occidentem Niceam habet : castrum in monte sublimi constructum, Emonis Chronicon, MGH, SS, t. 23, col. 32-33, cité par A. Venturini, * L'évolution urbaine de Nice du XI é siécle à la fin du XIVe siècle », Nice historique, 87 (1984), p. 4. 
l'époque médiévale : Montpellier, mentionné pour la première fois en 987 , Beaucaire, place sur un énorme rocher surplombant le Rhône, ou bien Grasse, où se réfugie l'évêque d'Antibes dont la ville, située sur la côte, est trop menacée par les raids maritimes d'al-Andalus. Le choix de ces sites, tout comme le rétraction défensive des anciennes cités romaines, est significatif de la militarisation accrue des villes, devenues de véritables repaires de gens d'armes 10 . Un nombre considérable de milites demeure donc dans ces centres urbains.

Pour des périodes si hautes, il est difficile, toutefois, d'apporter des chiffres précis corroborant ce poids démographique. Nos sources ne refletent pas moins la proportion élevee de chevaliers dans la population urbaine. A Nîmes, ils sont trente et un à prêter serment de fidélité au vicomte vers 1100 ; on en compte une cinquantaine en 1174 et environ cent en 122611 : cette ville, a l'écart des principaux axes commerciaux, dépourvue d'industrie, contient-elle plus de cinq mille habitants à la fin du XIIe siecle ? Dans la cite voisine d'Arles, dont la population atteint a peine dix mille habitants autour de 120012 , les sources livrent quelque trente noms de familles chevaleresques, chacune d'entre elles composée de plusieurs sous-lignages 13. Les membres de soixante maisons jurent leur foi à Guilhem VII de Montpellier en 1147 et a Guilhem VIII en 1190 14. Or, ces listes de milites prêtant serment de fidélité au seigneur de leur ville ne sont pas toujours completes; elles ne contiennent que le nom des chefs de lignages qu'on sait aussi plethoriques que polynucleaires 15. Autour de 1100, il n'est pas exagéré d'avancer que les chevaliers et leurs parents représentent environ un dixième de la population des cités méridionales.

9. H. Vidal, « Aux origines de Montpellier : la donation de $985 \star$, Bulletin historique de la ville de Montpellier, 5 (1985), p. 11-37.

10. G. Duby, « Les villes », op. cit. (n. 4), p. 118 et 120.

11. R. Michel, * Les chevaliers du château des Arènes de Nîmes aux XII' et XIII e siècles *, RH, 102 (1909), p. 49.

12. Pour cette date, E. Engelmann propose 5.000-6.000 habitants, contre 8.000-10.000 d'apres E. Baratier, chiffres tires de L. Stouff, « La commune d'Arles au XIII e siecle. A propos d'un livre recent $\star$, Provence Historique, 11 (1961), p. 298-299.

13. J.-P. Poly, La Provence, op. cit. (n. 4), p. 298-300.

14. Il est vrai que certains d'entre eux ne demeurent pas en ville, mais dans l'arrière-pays environnant, A. R. Lewis, Medieval Society in Southern France and Catalonia, Londres, Variorum, 1984, II, p. 566.

15. Sur la démographie des familles nobiliaires, nous nous permettons de renvoyer a $M$. Aurell, * Le lignage aristocratique en Provence au XIe siecle \#, Annales du Midi, 98 (1986), p. 149-163. 


\section{Tours et maisons fortes : le chateau en ville}

Une telle importance numérique et sociale de ces hommes en armes marque nécessairement le paysage urbain. L'exemple de Nîmes - « la fort cité garnie » de l'épopée française du cycle de Guillaume d'Orange 16 - est significatif de la présence spectaculaire de leurs demeures dans une cité. Dans cette ville, la plupart des chevaliers habitent, avec leur famille, dans un lieu que les textes appellent dès 876 le castrum Arenarum, l'ancien amphitheâtre romain transformé en citadelle imprenable. Dès l'époque wisigothique peut-être, le comte y installe son palais. Les guerriers de son entourage font aménager plusieurs maisons fortes dans ses portiques et galeries ou sur l'arène. Un document de 1157 y mentionne « la tour appelé épiscopale », « la tour des Cornut » et « la tour que Guilhem de Tour et son cousin Raimond tiennent de l'évêque "; cette même annee, un acte est passe * dans la tour qui jouxte l'église de Saint-Martin ». Avec Saint-Pierre, ce dernier lieu de culte est l'une des deux chapelles castrales construites, à l'aide de matériaux récupérés d'autres monuments romains, au cœur de l'amphitheâtre. Les arcades extérieures sont bouchées par des murs, encore visibles de nos jours : seules quatre portes permettent d'y pénétrer. Le tout est entoure d'un fosse 17. Les milites Arenarum, qui siègent dans le conseil de Nîmes dans un groupe distinct des « prud'hommes de la cite » (probi homines civitatis) 18 , sont vraiment une catégorie sociale a part, definie et par sa fonction militaire et par son implantation topographique.

D' autres vestiges romains sont convertis en chateau fort. A Narbonne ou a Nîmes, le capitole, jadis temple consacré a Jupiter, devient une forteresse 19. Le thếtre d'Orange est agence, à la façon des Arènes de Nîmes ou d'Arles, pour abriter une garnison militaire ; a Arles, un monument similaire, quoique de dimensions bien plus modestes, devient la tour de Roland ou demeure la maison de Carbonnières (figure 2). La rétilisation de l'enceinte de l'époque impériale aboutit, par ailleurs, à l'occupation à demeure de ses fortifications par les lignées chevaleresques. Dans le clos Saint-Nazaire de Béziers, deux tours de la muraille gallo-romaine, distantes d'une cinquantaine de metres, deviennent ainsi la tour de Bernard, du nom du chef de la maison des Sauvian, et la tour de Loup,

16. * Nîmes et sa solide fortification , * Nîmes avec ses hautes tours pointues , * Nîmes, puissante et bien pourvue », vers du Charroi de Nimes (v. 1150), cités par J. Le Goff, * Guerriers et bourgeois conquerants. L'image de la ville dans la littérature française du XIIe siecle $»$, dans Melanges C. Moraze, Toulouse, Privat, 1979, p. 114.

17. R. Michel, * Les chevaliers $\star$, op. cit., p. 46-47.

18. consilio proborum hominum civitatis et militum castri (...). In castro de Arenis, sub ulmo, in presentia tam militum quam burgensium, L. MEnand, Histoire civile, ecclesiastique et litteraire de la ville Nismes, Paris, 1750, PJ 26, p. 37-38 (6 VI 1161).

19. A. Dupont, Les cités, op. cit. (n. 5), p. 512-513. 
représentant d'un lignage urbain qui exerce la justice au nom du vicomte Bernard Aton (1074-1129) ; elles présentent un plan circulaire, le premier niveau aveugle servant de soubassement qui supporte un ou deux étages en plein cintre (figure 3) 20. Dans la cité de Narbonne, la tour Mauresque, construite près de la porte Aiguière qui ouvre la voie domitienne sur le pont de l'Aude, est reliee a la tour de l' archidiacre Guifred ; au nord, la tour Carree, proche de la porte Royale, est, comme les précédentes, la propriété de l'archevêque 21 . Les nouveaux pouvoirs urbains renforcent, en définitive, certains ééments du dispositif défensif romain et en accordent la garde à leurs fideles.

Les portes de l'enceinte de la cité subissent le même sort, devenant une maison forte où demeurent un chef de guerre et ses hommes. A Barcelone, les sorties du decumanus, à savoir Castellnou, à l'est, et Castellvell, à l'ouest, aux noms significatifs de vieux et nouveau château, appartiennent au comte : Castellvell devient le centre névralgique de la ville, tandis que se développe autour de lui le bourg de Vilanova ; il est cédé au vicomte, puis au vicaire, représentants de la justice comtale. Dans cette cité, la porte de l'évếque au nord et de Regomir au sud sont, en revanche, tenues par les guerriers de l'épiscopat (figure 4) 22. Les anthroponymes de quelques chevaliers nîmois, comme Bernard de la Porte Vieille ou Peire de la Porte de Rades, traduisent un lieu de résidence identique ; toujours a Nîmes, les textes citent le « castrum de la porte d'Espagne » et le « castrum qu'on dit porte d'Arles » 23. La plus septentrionale des sorties de l'enceinte de Toulouse est enfin appelée d'après le nom d'Arnaud Bernard, membre de la famille de Cap du Bourg, fondatrice, avec le monastère de Saint-Sernin, de la sauvete de Matepezoul dans la Grande Lande vers 1080 (figure 5) 24. On devine, par conséquent, toute l'importance des portes de la muraille, lieux obligés de passage pour celui qui voudrait entrer ou sortir de la ville ; les chevaliers-portiers qui y habitent et qui les gardent contrôlent tout un pan de la vie politique et économique de leur cité.

Les textes mentionnent, en outre, les demeures de maints chevaliers, dispersées à l'intérieur de l'ancienne cité et, parfois même, dans ses bourgs. Ils les dé-

20. C. Duhamel-Amado, « De la cité wisigothıque à la ville médiévale (Ve-XIIe siècle) », dans J. Sagnes (sous la direction de), Histoire de Béziers, Toulouse, Privat, 1986, p. 79, d'après la thèse inédite d'Y. Esquieu

21. A. Dupont, Les cités, op. cit. (n. 5), p. 506-507.

22. S. Bensch, Barcelona, op cit. (n. 4), p. 32. Les chevaliers du vicomte d'Avignon surveillent, en son nom, les portes Ferruce et Aiguière, J.-P. Poly, * De la citadelle du fleuve à la capitale de la chrétiente (VII e-XIV e siècles) », dans Histoire d'Avignon, Aix, Edisud, 1979, p. 138.

23. R Michel, \& Les chevaliers $»$, op. cit. (n. 11), p. 46, n. 3, p. 48 , n. 7 et p. 49 , n. 1 . ; cas trum de porta Spana, C. Devic, J. Vaissette, Histoire générale du Languedoc, Toulouse, 1875 (= HGL), t 5, col. 428, $\mathrm{n}^{\circ} 211$ (14 XX 1037).

24 J. H Mundy, Liberty, op cit. (n 4), p 10 et 27. 
signent, presque toujours, sous le vocable générique de turris. Au XIIe siecle, ces documents sont particulièrement explicites pour Toulouse. C'est dans le Bourg de cette ville que la famille Caraborda - a laquelle appartient Oldric, l'un des principaux capitulaires du gouvernement municipal en 1176 - détient une tour; les Roaix se partagent, au même endroit, la proprieté d'une autre tour avec Saint-Sernin, monastère auquel les Castelnau vendent leurs droits sur une maison en pierre et une tour en 1171. Plus au sud, dans la Cité, les Barrau possedent une « tour ronde », sur une rue qui porte le nom d' Arnaud, chef de leur lignage, et dont les habitants leur versent un cens d'oublies. Peu avant 1216, Raimond Mascaron donne, au monastère de Boulbonne, une tour dont se sert Simon de Montfort pour imposer sa domination sur la ville 25 . Au-delà du Rhône, en Provence, dans la ville basse de Grasse, quartier bâti entre 1170 et 1190 , ces mai sons fortes sont placées au bout des rues dont elles contrôlent l'accès (figure 6). Aux allures militaires, la tour aristocratique est un élément courant de la topographie urbaine.

La qualité et la solidité de sa construction tranchent sur les taudis qui l'entourent. A Cruas et à Saint-Marcel (Ardèche), on peut dégager quelques caractéristiques communes de huit de ces maisons de chevaliers, conservées a l'état fragmentaire : bel appareil régulier en pierres de taille, chaînage d'angle lisse, porte en plein cintre a l'étage, où l'on accède par une échelle extérieure, fenêtres géminées à colonnettes surmontées de chapiteaux et décors sculptés 26. Dans le clos Saint-Nazaire de Béziers, les Isembert, parents des Rainard, vicomtes de cette ville au $X^{e}$ siecle, possedent une demeure de vastes dimensions comportant plusieurs cours, divers bâtiments annexes, une terrasse et un jardin ; elle est flanquée d'une tour 27. Ces grandes bâtisses sont le point d'ancrage des lignages citadins, qui s'en servent afin d'etablir leur seigneurie sur une portion de la ville et afin de se protéger des attaques éventuelles de leurs ennemis.

Vestiges du fractionnement du ban, beaucoup d'entre elles sont, au XIIIe siècle, détruites par les autorités royales qui tentent de contrôler de façon unitaire et exclusive l'espace urbain. Guillaume de Puylaurens rapporte que, après la conquête de Toulouse, Simon de Montfort nivelle « les fossés et les tours des maisons fortes qui se trouvent à l'intérieur de la ville » pour prévenir toute révolte 28 . En 1226, les troupes de Louis VIII qui soumettent le Languedoc prennent des mesures identiques à l'encontre des chevaliers de Nîmes et d'Avignon :

25. Ibid. p. 227, n. 33, p. 228, n. 36, 35 et 39, p. 229, n. 40.

26. D. Ferre, J.-C. Poteur, * Les demeures nobiliaires dans les consulats aristocratiques (Grasse, Cruas, Saint-Marcel d'Ardeche) », dans Le village. Actes des journées d'histoire régionale de Mouans-Sartoux (16-17 mars 1984), Mouans-Sartoux, 1984, p. 79-89.

27. C. Dubamel-Amado, « De la cité », op. cit. (n. 20), p. 78.

28. fossata et turres domorum fortium infra villam, Guillaume de Puylaurens, Chronique (1203-1275), ed. J. Duvernoy, Paris, CNRS, 1976, p. 92, ch. 24. 
les premiers sont délogés des Arènes et dispersés dans des maisons en ville 29 ; selon les chroniqueurs officiels du Capetien, le sort des seconds, dont « les trois cents maisons à tour 30 » sont détruites, est encore moins enviable (figure 7). Par ces démantèlements, l'administration princière affiche une volonté claire de s'opposer à toute forme de résistance à la croissance des nouvelles structures étatiques ; le rôle politique des chevaliers en sort d'autant plus diminué. A l'orée du XIIIe siecle, cette situation contraste avec la période précédente où les milites tiraient profit de leurs tours, de leurs portes fortifiées et de leur enceinte pour s'affirmer dans la vie municipale.

\section{Fiefs : le guet contre des rentes}

Aux XIe et XII siècles, les chevaliers tiennent souvent leur maison forte d'un seigneur laiic ou ecclésiastique, à l'égard duquel ils se sont engagés par les liens féodaux. Au sommet de la hiérarchie des pouvoirs urbains, le comte ou le vicomte se partagent avec l'évêque l'espace de leur cité ; la séparation de la ville en deux secteurs nettement différenciés, l'un relevant du comitatus et l'autre de l' episcopatus, est l'une des conséquences directes de la reforme grégorienne. La ville des tours ou épiscopale de Marseille, distincte de la ville basse ou vicomtale depuis 1073, connaît même le détachement de toute sa partie occidentale, devenue la ville de la prévôté ou de l'œuvre depuis le milieu du XIIe siècle au profit du chapitre cathédral 31. Les seigneurs laïcs délèguent parfois une partie de leurs pouvoirs à des vicaires, devenus fort puissants a Montpellier où ils fomentent, en 1141, une revolte qui chasse Guilhem VI (1121-1149) de la ville pendant deux ans 32. Partout des murs, des fossés et des chaînes marquent les limites entre les différents quartiers qui se trouvent sous la juridiction de l'arche-

29. R. Michel, L'administration royale dans la sénéchaussée de Beaucaire au temps de saint Louis, Paris, 1910, p. 132

30. Trecenta domus turrales, qua in villa essent, et omnes muri circumquaque solo diruti cocequantur, Gesta Ludovici VII, RHF, t. 17, p. 310A. Ce chiffre, destiné à glorifier le triomphe de l'armée française, victorieuse dans son siège d'Avignon, est bien exagére.

31. V.-L. Bourrilly, Essai sur l'histoire politique de la commune de Marseille des origines a La victoire de Charles d'Anjou (1264), Aix, 1926, p. 15-16. A Agde, l'éveque parvient même à accaparer complettement les droits du vicomte, qui les lui cède en 1187 , A. Castaldo, L'Eglise d'Agde (Xe-XIIle s.), Paris, PUF, 1970, p 58. A Lodève, la toute-puissance de l'évêque est similare.

32. A. Dupont, Les cites, op. cit. (n. 5), p. 688-691 ; A.R. Lewis, Medieval Society, op. cit. (n. 14), II, p. 567-568. Les Aimon, branche cadette des Guilhem qui accapare le vicariat, ont reçu un important château en ville : castellum quod est situm juxta portam Sancti Nicholai in Montepessulano, sicut est clausum cum turribus et muris, cum ingressu et regressu, A. Germain-Martel, Liber instrumentorum memorialium. Cartulaire des Guillems de Montpellier, Montpellier, 1884-1886, p. 209, $\mathrm{n}^{\circ} 100$ (24 I 1104). A la même époque, le vicaire Berenguer Ramon se révolte à Barcelone, mais par la suite les détenteurs de cette charge, d'origine relativement modeste, font preuve de soumission au comte (S. Bensch, Barcelona, op. cit. (n. 4), p. 63-72). Sur le vicariat a Marseille autour de 1200, cf. V.-L. Bourrilly, Essai, op. cit. (n. 31), p. 40-43. 
vêque, de l'évêque ou du prévốt, ou bien du comte, du vicomte ou du vicaire. Ce cloisonnement n'efface pas d'un trait les conflits qui opposent ces seigneurs ; il les attise plutôt.

Pour triompher sur ses ennemis ou, tout simplement, pour conserver son pouvoir, aucun des maîtres de la ville ne saurait se passer du service d'une troupe de milites. Pris au hasard d'une abondante documentation, deux actes languedociens montrent toute l'importance dont jouit, dans cette situation belli queuse, la féodalité qui met ces chevaliers sous la dépendance d'un seigneur urbain. Le 26 novembre 1112, Ricard de Millau (1106-1121), archevêque de Narbonne, et le vicomte Aimeric II (1105-1134) règlent le différend qui les oppose au sujet du sel, de la justice et des droits sur les péages, les moulins et les marchés de leur ville 33 ; une clause de ce partage spécifie : «A propos des tours et des maisons de la cité, dont se plaint l'archevêque, qu'on choisisse des prud'hommes, fidèles de chacune des deux cours, qui établissent la paix et la concorde entre l'archevêque et le vicomte. Que les feudataires (fevales) comparaissent devant ces prud'hommes et, une fois leurs arguments entendus, que ceux-ci émettent leur jugement. Qu' Aimeric s'amende pour les dommages qu'il a portés aux feudataires de l'archevêque ${ }^{34}$. Voici le second exemple : entre 1175 et 1182, l'évêque d'Agde cède l'immense fief de Vias, situe à cinq kilomètres de la ville, à l'un de ses chevaliers, « en voulant récompenser le service et l'aide que toi, Joan d'Avias, nous as rendus, à nous et à notre Eglise, en ce temps où

33. Sur le long conflit entre l'archevêché et la vicomté à Narbonne, cf. J. Caille, * Origine et développement de la seigneurie temporelle de l'archevêque dans la ville et le terroir de Narbonne (IXe-XIIe siècles) \#, dans Narbonne. Archéologie et histoire, Montpellier, Fédération Historique du Languedoc méditerranéen et du Roussillon, 1973, p. 9-36.

34. De turribus et mansis civitatis, unde conqueritur archiepiscopus, eligantur probi viri utriusque curia fideles, qui pacem et concordiam velint inter archiepiscopum et vicecomitem, et veniant fevales ante eorum prasentiam et, auditis rationibus, faciant quod ipsi judicaverint. Fevalibus archiepiscopi emendet per eum Aymericus injurias quas eis facit, HGL, t. 5, col. 832-833, n ${ }^{\circ}$ 445. Le terme fevales pose un problème de traduction : E. Magnou-Nortier (La societé laíque et l'Eglise dans la province ecclésiastique de Narbonne (zone cispyrenéene) de la fin du VIIle au XIe siecle, Toulouse, Publications de l'Université de Toulouse-le-Mirail, 1976, p. 229) et C. Duhamel-Amado (La famille aristocratique languedocienne. Parenté et patrimoine dans les vicomtés de Béziers et d'Agde (900-1170), These d'État multigraphiée, Université de Paris IV, 1993, t. 1, p. 368-369) remarquent qu'il s'agit de ministériaux, d'agents seigneuriaux d'origine roturière, préposés à la gestion du domaine et à des tâches plus complexes. Dans le document de 1112 à Narbonne, cependant, la mention explicite de tours, leur role actif dans le proces et leur indemnisation nous semble renvoyer plutôt à des feudataires du groupe nobiliaire. Cette définition est adoptée par A. Dupont dans son étude de l'acte de 1112 : « nous pensons qu'il y a lieu d'assimiler ces fevales à des milites $»$, Les cites, op. cit., p. 671. C. Duhamel-Amado, trouve, d'ailleurs, fevales dans son acception de * feudataires * dans un autre acte de Bernard Atton date de 1127, ibid., p. 359. 
nous menons une guerre contre le vicomte »35. Dans les cités de Narbonne et d'Agde, comme partout ailleurs, tout seigneur accorde des fiefs à des chevaliers devenus ses fideles.

Des rites entérinent cette entrée des guerriers dans la dépendance honorable d'un maître. Le serment de fidélité, prêté sur des reliques, apparaît le plus souvent dans la documentation. Il ne comporte que des obligations négatives pour le fidele, qui s'engage à ne pas nuire à son seigneur, à garantir sa sécurité phy sique et a conserver ou a récupérer ses biens ${ }^{36}$. L'hommage, tout comme le terme « vassal », n'apparaît de façon systématique dans les sources qu'a partir des années 1150 37. Il est, d'abord, prêté aux évêques : des légistes professionnels issus de l'entourage épiscopal et du chapitre cathédral formalisent, a l'époque, les relations féodo-vassaliques, lui donnant un rituel, un vocabulaire et un cadre juridique plus complet et précis ${ }^{38}$. C'est parmi les milites citadins des seigneurs ecclésiastiques que ces nouveaux modes d'entrée en vassalité se répandent en premier lieu 39. La foi, et dès la fin du XII e siècle l'hommage, placent en somme le chevalier qui l'a juré sous la coupe du seigneur.

Il en découle un certain nombre d'obligations pour ce fidèle. Dans les villes des Trencavel, la « châtellenie » (castellania, castlania), la charge de garder physiquement une forteresse d'un prince laïc ou ecclésiastique, est une institution fort courante ; ce mode de délégation de pouvoir n'implique pas une liberté de manœuvre absolue pour le «châtelain » (castellanus, castla), qui peut être

35. Volens remunerare servitium et obsequium quod tu, Johannes de Aviatio, nobis et Ecclesie nostre impendisti presenti tempore guerre quam habemus cum vicecomite, cité par A. Castaldo, L'Eglise, op. cit. (n. 31), p. 64.

36. A Nîmes, les Arènes sont au centre de ces serments : Ego Ugo de Bredeto, filius Adalacie, tibi Bernardo Atoni vicecomiti, filio Guilelme, non tollam castrum de Arenis, videlicet fortitudines que hodie ibi sunt et in antea ibi erunt, nec aliquid de eo (...). Et si quolibet modo aliquis vel aliqua predictum castrum vel aliquid de eo suprascripto tolleret, ego cum illis donec recuperaretur finem vel societatem non haberem, nisi causa recuperandi illud castrum, $\mathbf{A}$. Teulet, Layettes du tresor des chartes, Paris, 1863, t. 1, p. 107, n 253 (v. 1174).

$37 . \kappa$ Les châtelains qui jurent fidelité aux Trencavel ne deviennent pas formellement leurs vassaux : ils ne leur prêtent pas d'hommage et les châteaux ne sont pas donnés en fief. Cependant, le serment prêté pour un château vaut remise en alleu de ce dernier au vicomte, car son détenteur promet de le rendre a toute réquisition. $»$, J.-L. Biget, * Cathares du pays de l'Agout (12001300) \#, dans Europe et Occitanie. Les pays cathares, Carcassonne, C.E.C., 1992, p. 277. Les cas d'hommage qu'on rencontre avant les années 1150 concernent surtout des guerriers vaincus se rendant à leur ennemi.

38. G. Giordanengo, Le droit féodal dans les pays de droit écrit. L'exemple de la Provence et du Dauphine, XIIe -début XIVe siécle, Rome-Paris, De Boccard, 1988, p. 93-109. Exemple de feudum honoratum, forme savante du fief de reprise, à Nimes, en 1149, dans $R$. Michel, * Les chevaliers $»$, op. cit. (n. 11), p. 48, n. 7 .

39. M. Aurell, Une famille de la noblesse provençale au Moyen Age : les Porcelet, Avignon, Aubanel-Distique, 1986, p. 80-82. 
démis de ses fonctions s'il ne se plie pas aux exigences de son seigneur 40 . En 1126, après avoir écrasé la révolte des habitants de Carcassonne 41, Bernard Aton remplace les castellani qui l'ont trahi par seize autres guerriers, tenus de sejourner pendant huit mois en ville, avec leurs hommes et leur famille, pour garder chacun l'une des tours de l'enceinte et pour y faire le guet 42 . Les chevaliers citadins sont, en outre, astreints aux formes de concours que les autres fidèles apportent a leur seigneur : ils prennent part à ses chevauchées, siègent dans son tribunal, se portent ses garants et ses otages ou deviennent ses champions dans les duels 43 . De nature militaire, judiciaire ou policière, l'aide et le conseil sont le lot des chevaliers citadins.

Le service féodal apparaît sous un jour bien theâtralisé à la cour de l'évêque de Béziers. Pons de Corneilhan (1123-1169) y est le titulaire « du fief qu'on appelle la sénéchaussée (senescallia) », pour lequel une notice de juillet 1153 spécifie les droits et les devoirs qu'il comporte 44 . Ce chevalier provient d'une maison attachée à l'épiscopat : en 1050, Bernard Gairald, son ancêtre, est déjà le sénéchal de l'évêque ; pour ces fonctions, les Corneilhan détiennent de nombreuses rentes, moulins et domaines du temporel de l'Eglise biterroise 45 ; plusieurs d'entre eux deviennent chanoines dans le chapitre Saint-Nazaire ${ }^{46}$. Or, la senescallia des Corneilhan doit être bien comprise au sens étymologique, archaique, du service a table que « le plus vieux des valets " (en francique, sini skalk) effectuait en faveur d'un maître à une époque ancienne où la domesticité était encore source de puissance et de richesse. Aux termes de l'accord de 1153, Pons reçoit le quart d'un setier d'avoine, sans doute pour ses chevaux, chaque

40. Communication d'H. Débax sur la féodalité dans le cartulaire des Trencavel, prononcée le 28 aout 1995, au colloque de Couiza (Aude), Les voies de l'herésie : le groupe aristocratique en Languedoc (XI'-XIITe siècles). 8e session d'histoire médiévale du Centre d'Etudes Cathares.

41. Ces événements sont décrits par une notice rédigée vers 1170 à la cour de Barcelone, Arxiu de la Corona d'Aragó, Ramon Berenguer IV, extra inventaris, $n^{\circ} 2504$, éd. HGL, t. 5, col. 31-33, $n^{\circ}$ 6. Cf. en outre J.-M. Carbasse, « Des Carolingiens à la croisade (fin VIII e-XIIIe siècle) », dans Histoire de Carcassonne, Toulouse, Privat, 1984, p. 44-49.

42. Sic donamus tibi ad fevum et propter castellaniam in tali convenientia ut per quemque annum, cum tuis hominibus et tua familia, facias stationem in Carcassona per VIII menses et pradictam turrem custodire et gaitare facias omni tempore et ipsam urbem custodias, HGL, $t$, 5 , col. 919-926, $\mathrm{n}^{\circ} 489$ (12 I 1126-3 IV 1127): passé le lundi 12 janvier, le premier document de cette série doit, d'après le style de l'incarnation, être de 1126 n.s.

43. P. Bonnassie, La Catalogne du milieu du Xe d la fin du XIe siecle. Croissance et mutations d'une société, Toulouse, Publications de l'Université de Toulouse-le-Mirail, 1976, p. 729-730 et 770 ; C. Duhamel-Amado, La famille, op. cit . (n. 34), t. 1, p. 371-377.

44. de controversiis, quas ad invicem habebant de quibusdam beneficiis et serviciis illius feudi quod vocatur senescallia, HGL, t. 5, col. 1169-1171, n 598.

45. C. Duhamel-Amado, La famille, op. cit. (n. 34), t. 2, p. 79-90.

46. H. Vidal, Episcopatus et pouvoir épiscopal a Béziers a la veille de la croisade albigeoise (1152-1209), Montpellier, 1951, p. 36-38. 
nuit que l'évêque dort à Béziers; il conserve plusieurs morceaux des porcs consommés au palais épiscopal, à condition que ses hommes s'occupent de les tuer, de leur enlever les soies, de les dépecer et de les apprêter; il garde, en outre, la tête, les pieds et les abats des vaches, moutons et agneaux ; il récupère, enfin, le vin des coupes et les autres reliefs des banquets ainsi que le gras des chaudrons et casseroles. En contrepartie, lors des banquets que donne l'évêque quand il tient sa cour, il assure personnellement le service à table avec l'un de ses chevaliers qui porte un flambeau et verse le vin 47 ; deux de ses hommes travaillent à la cuisine où l'éclairage et le sel sont aux frais de Pons 48. De tous temps, le repas du chef revêt une forte signification politique et sociale ; dument mis en scène, il sert à exalter sa puissance et à faire accepter sa place au sommet de la hiérarchie par ceux qui le nourrissent de leur travail 49. Dans la célebration du pouvoir de l'évêque de Béziers, la domesticité des Corneilhan, serveurs autant que serviteurs, répond à une étiquette stricte qui manifeste avec évidence la soumission des milites à leur maître.

Quoique moins théâtrales, stéréotypées et conventionnelles que pour la senescallia, les obligations de la castlania, garde d'un point fortifie, comportent de même des compensations pour les fidèles. Une charte nîmoise cite « la "châtellenie" des Arènes et le fief que les hommes détiennent pour cette "châtellenie" $50 »$; l'acte rendant, en 1126, seize chevaliers responsables de la surveillance de l'enceinte de Carcassonne mentionne les maisons et les terres que le vicomte leur donne « en fief pour la "châtellenie" 51 ». Un contre-don est ainsi la récompense donnée par le seigneur pour le service militaire.

Ce fief (fevum) ou bénéfice (beneficium), que le maître accorde à son fidèle, peut être de nature très variée. La maison forte (stare, turris), demeure du che-

47. Cum episcopus curiam tenuerit, serviat Poncius ad epulas cum uno milite vel filio militis et cum primorum prandium ibi commendant [...] Habeat etiam Poncius, cum episcopus curiam tenuerit, hominem suum qui cantarum teneat et manu candelam ibi habeat et vinum in ciphos fundat, HGL, t. 5, col. 1169-1171, $\mathrm{n}^{\circ} 598$.

48. Sur les enjeux que pouvait représenter le contrôle de la cuisine épiscopale, véritable lieu de luttes pour le pouvoir, cf. les plaintes de l'hagiographe d'Adelbert de Tournon ( $\dagger$ 1187), évêque de Mende, contre le comte de Barcelone et les chevaliers de l' aristocratie locale, qui choisissaient parmi leurs fidèles l'intendant de la cuisine épiscopale, passant outre aux prérogatives d'Adelbert, Chronicon breve de gestis Aldeberti, éd. C. Brunel, Les miracles de Saint-Privat, suvis des opuscules d'Adalbert III, évêque de Mende, Paris, 1912, p. 125-139, n 4.

49. Cf. M. Aurell, O. Dumoulin, F. Thelamon (sous la direction de), La sociabilite d table. Commensalité et convivialité à travers les ages, Rouen, Publications de l'Université, 1992, p. 118-170.

50. El caslaniam Arenarum et fevum quod homines tenent per caslaniam castri Arenarum, HGL, t. 5, col. 1082, n 563 (5 V 1146).

51. Donamus tibi ad fevum et propter castellaniam totum illum honorem, HGL, t. 5, col. 920, $n^{\circ} 489$ (12 I 1126). 
valier et de sa parentèle, entre souvent dans cette catégorie 52 : dans maintes chartes, elle est explicitement concédée en fief par le seigneur. Elle comporte parfois des jardins, à une époque où le tissu urbain, encore très lâche, comprend de nombreuses terres destinées à l'agriculture 53. On y construit, toutefois, de plus en plus d'immeubles, tandis que grandit la population urbaine : le prix du sol augmente en ville, notamment à partir des années 1150, celles du démarrage de l'artisanat et du commerce local 54 . Les chevaliers s'adonnent à la speculation foncière, transformant leurs champs et potagers en terrain bâti ; la location de ces immeubles leur fournit une rente enrichissante 55. Ils ont reçu, pareillement, quelques domaines dans l'arrière-pays de leur cité : la famille arlésienne des Rapina détient ainsi des granges à Meyrane, qui leur ont été cédées par les vicomtes de Marseille, le village de la Furane en Camargue au nom des Baux ainsi que le fief de Paperaria de l'archevêque d'Arles ; cette pluralité de seigneurs augmente d'autant plus leur patrimoine 56 . Les chevaliers sont les principaux détenteurs des terres urbaines et suburbaines qu'ils ont obtenues en fief de leurs seigneurs.

D'autres droits sont aussi lucratifs. Les moulins et les fours, monopoles aristocratiques, connaissent une activité croissante, puisque leur farine et leur pain assurent le ravitaillement de villes chaque jour plus peuplees ; ils appartiennent souvent aux chevaliers citadins qui disposent des capitaux nécessaires pour assurer leur construction et leur entretien 57. Les taxes des marchés urbains finissent souvent dans l'escarcelle de ces milites, détenteurs des leudes perçues sur les produits exposés sur les étals 58. Au cours d'une période de renouveau commercial, les péages sur les routes, que nos guerriers sont censées protéger, leur

52. Ego Bermardus Ato, Nemausensis et Agathensis vicecomes, (...) laudo et in perpetuum ad feudum concedo tibi Bernardo de Paragio et tibi Ugoni de Cervaria et tuis stare totum de Arenis in quo est ecclesia Beati Petri, quod fuit Petri Guirardi, A.N., J 323, n 46, cité par R. Michel, « Les chevaliers », op. cit. (n. 11), p. 48, n. 2 (XI 1175).

53. Dono tibi ad feudum ipsos mansos cum exeos et regresseos suos, cum ipsas bordarias et cum ipsos ortales et cum ipsas adjacentias, HGL, t. 5, col. 487, $n^{\circ} 246$ (v. 1056).

54. S. Bensch, Barcelona, op. cit. (n. 4), p. 92.

55. * La plupart des immeubles de la cité et du bourg leur appartenaient [aux milites] et leur donnaient un revenu important $\%, R$. Limouzin-Lamothe, La commune de Toulouse et les sources de son histoire (1120-1249), Toulouse-Paris, 1932, p. 228.

56. Le fait de dépendre de plusieurs seigneurs donne, par ailleurs, \& une grande indépendance au vassal », J.-P. Poly, La Provence, op. cit. (n. 4), p. 291.

57. Voici deux exemples nîmois : ego Petrus Bernardus de Capitolio [de la maison carrée] trado in perpetuum Deo et Sancti Salvatori de Fonte (...) omnes partes quas habeo in carto molendini superioris de fonte, L. Ménard, Histoire civile, op. cit. (n. 18), PJ 28, p. 39 (1170); in perpetuum ad feudum concedo (...) furnum de Bocharia, A.N., J 323, $\mathrm{n}^{\circ} 46$, cité par R. Michel, « Les chevaliers », op. cit. (n. 11), p. 48, n. 2 (XI 1175).

58. J.-P. Poly, La Provence, op. cit. (n. 4), p. 302 ; A. Castaldo, Le consulat médiéval d'Agde, Paris, Picand, 1974, p. 58. 
rapportent gros 59 . Il en va de même sur les fleuves et rivières : les chevaliers de Toulouse exigent le portage sur les bateaux de la Garonne 60 ; ceux d'Arles ou d'Avignon soumettent les nefs et radeaux du Rhône et de la Durance à des tonlieux 61. Certains d'entre eux jouissent du droit exclusif d'exploiter les rares bacs qui permettent de traverser ces cours d'eau ; ce monopole leur procure des profits considérables. Ils s'opposent à la construction de ponts en pierre qui pourraient les concurrencer : vers 1177 , l'érection de celui d'Avignon par saint Bénézet et ses frères pontifes porte préjudice aux Amic, descendants des vicomtes de la ville, à l'évêque et à plusieurs chevaliers, qui exigent une lourde indemnisation au terme d'un long procès 62 . L'essor des échanges favorise, enfin, les milites des villes portuaires, qui se partagent les taxes sur les cargaisons des bateaux qui les accostent : a Saint-Gilles, nombreux sont les feudataires de l'abbe qui participent à ces profits douaniers 63 . Plus que les marchands peutêtre, les chevaliers des villes deviennent les principaux bénéficiaires de la renaissance du commerce.

Leurs coffres se remplissent des pièces d'argent que l'atelier de Melgueil répand, parmi tant d'autres, en Occitanie. L'ampleur de leurs disponibilités monétaires est parfois impressionnante. En 1161, a Montpellier, Guilhem Peire verse cent marcs d'argent à Raimbaud d'Orange, seigneur d' Aumelas, pour le château de Miraval qui lui est hypothéque 64. En juin 1163, Peire Girard des Arènes de Nîmes est remboursé d'une partie des cinq mille cinq cents sous que lui doit le comte de Toulouse ; il reçoit, pour l'occasion, des droits sur le marché de SaintGilles et sur le péage de Vallis Aqueria 65. En avril 1176, Bertrand Porcelet prête vingt mille sous au comte de Barcelone, qui lui confirme les taxes qu'il perçoit sur les nefs du Rhône, sur les marchés d'Arles et sur les pâturages de son arrière-pays 66 . En consentant des prêts à leur seigneur, ces chevaliers n'ac-

59. Exemples de péages sur la piste de Béziers à Narbonne et à Montpellier cédés en fief ou en gage dans A. Dupont, Les cités, op. cit. (n. 5), p. 599.

60. J. H. Mundy, Liberty, op. cir. (n. 4), p. 259 n. 8 et p. 260 n. 10.

61. J.-P. Poly, La Provence, op. cit. (n. 4), p. 301.

62. J.-P. Poly, « De la citadelle », op. cit. (n. 22), p. 150. Pour Toulouse, cf. R. LimouzinLamothe, La commune, op. cit. (n. 55), p. 406-407, $\mathrm{n}^{\circ} 74$ (20 XII 1222).

63. De cetero monasterium Sancti Egidii libere habeat et quiete possideat ipsum super portorium. Et totum quod ibi habent ex integro feudales similiter nomine monasterii perpetuo habeant et possideant, L. Ménard, Histoire civile, op. cit. (n. 18), PJ 24, p. 36 (24 V 1160).

64. A. Germain-Martel, Liber, op. cit. (n. 32), p. 523-525, $\mathrm{n}^{\circ} 339$. L'importance de cette somme pousse A. R. Lewis (Medieval Society, op. cit. (n. 14), I, p. 59, n. 50) a considérer Guilhem Peire comme bourgeois, mais rien ne permet de l'affirmer à partir de la documentation de l'époque qui présente toujours les membres de sa famille comme des milites.

65. HGL, t. 5 , col. 1267, $\mathrm{n}^{\circ} 652$ (1163).

66. A.D. Bouches-du-Rhône, B 288. Le prix d'un cheval ordinaire est alors de quarante sous, P.-A. Amargier, Cartulaire de Trinquetaille, Aix, Publications Universitaires des Lettres et Sciences Humaines, 1972, p. 48, $n^{\circ} 56(1160-1167)$. 
complissent qu'un devoir féodal fort traditionnel dans les pays méditerranéens ; ils reçoivent en gage des revenus tirés des tonlieux, des leudes ou des péages. Cette sorte de mise a ferme des taxes sur le commerce profite aux milites citadins, détenteurs de sommes d'argent considérables.

Nos chevaliers manient, en effet, trop souvent des espèces sonnantes et trébuchantes. Ils presentent parfois le visage du banquier ou du percepteur, a l'opposé de l'image traditionnelle d'une noblesse rétive aux activités financières. Ils possèdent des revenus, provenant de la fiscalité qui détourne une partie des bénéfices de l'artisanat et du commerce à leur profit. Les fiefs-rente viennent ainsi compléter un patrimoine dans lequel les terres situées à l'intérieur et à l'extérieur des villes occupent, par ailleurs, une place considérable. Ces terrains, loués à de nouveaux venus qui y construisent une maison, leur fournissent des cens de bon rapport. S'ils sont, en revanche, voués à l'agriculture et à l'élevage, leur production est ecoulée sur les marchés urbains dont grandit la demande. Les chevaliers des villes tirent largement avantage de la prospérité générale. Leur pouvoir banal et leurs fiefs leur garantissent une portion considérable du fruit du travail des citadins qu'ils sont censés défendre.

Responsables des principaux points fortifiés des villes, les milites s'adonnent, somme toute, a la guerre au cours d'une période trouble. Le guet et la chevauchée sont leur occupation principale. Au service d'un prince, auquel ils prêtent serment de fidélité, ils bénéficient de sa genérosité, occupant ses terres et percevant ses taxes. Ils sont, de la sorte, immergés dans un réseau féodal. Ils subissent, en contrepartie, la contraignante autorité du maître, quoiqu'ils puissent profiter de la multiplicité de seigneurs pour mener, avec une certaine marge de manœuvre, une politique personnelle plus ou moins prestigieuse au gre de leurs revenus et de l'étendue de leur propre clientèle. Ces chevaliers vivent avant tout pour la guerre. Leur fonction militaire suffit-elle, cependant, à définir leur statut?

\section{Un statut social flou}

Le miles est aisément reconnaissable par ses concitoyens. Il bénéficie de la publicité de certains rites qui le désignent en tant que chevalier devant la communauté : la remise des armes ou adoubement, bien attesté dès le milieu du XIIe siecle, permet à un adolescent d'intégrer le groupe des guerriers spécialisés dans le combat à cheval 67 ; le miles prête, en outre, aux yeux de tous, serment de fi-

67. Cum uno milite vel filio militis, HGL, t. 5, col. 1169-1171, $\mathrm{n}^{\circ} 598$ (VII 1153), acte sur la senescallia de Béziers, où Pons doit assurer le service à table avec $*$ un chevalier ou un fils de chevalier $*$, sous-entendu pas encore adoube. Vers 1150, l'article 8 des Usages de Barcelone mentionne le tarif des amendes d'un fils de chevalier, qui perdrait ses privilèges s'il ne le devenait 
délité à son seigneur. Il se déplace, de façon ostentatoire, en armes 68 . Il accomplit des tâches specifiques, parfaitement définies autour de 1150 par les Usages de Barcelone, code législatif promulgue à la cour comtale : « Perd la chevalerie (cavalleria) celui qui ne possède pas de cheval ni d'armes, celui qui ne détient pas un fief de miles, celui qui ne va pas aux chevauchées et aux osts, ni aux plaids et aux cours en tant que miles, à moins qu'il en soit empêché par la vieillesse 69. „ Le chevalier combat, en définitive, sur son destrier, tire ses ressources d'un fief et rend justice avec son seigneur.

Parce qu'il fait la guerre à cheval, le miles ou cabalarius ne saurait être confondu avec les autres membres du patriciat urbain 70. Par contraste, le bourgeois se contente d'intégrer la milice de sa ville en tant qu'homme à pied ou sergent 71 . Au XIIIe siècle, cette dualité des fonctions militaires transparaît dans le tympan sculpté du palais communal d'Avignon, où figurent seulement deux personnages, un chevalier monté, portant une lance à penon, et un piéton, l'épée au clair.

pas avant l'âge de trente ans: Filius autem militis emendetur ut pater usque ad XXX annos; deinde ut rusticus, si non factus fuerit miles, F. Valls Taberner, Los Usatges de Barcelona. Estudios, comentarios y edición bilinglle del texto, Málaga, Promociones Publicaciones Universitarias de Barcelona, 1984, p. 76. Pour la date des différents aricles de ce code, cf. F. Udina, A. Udina, * Consideracions a l'entorn del nucli originari dels Usatici Barchinona ", dans La formació $i$ expansio del feudalisme catald. Homenatge a Santiago Sobreques $i$ Vidal, Gérone, Collegi universi tari, 1985-1986, (Estudi general, 5-6), p. 87-107. Pour l'adoubement dans la littérature d'oc, en particulier dans Giran de Roussillon, cf. L. M. Paterson, The World of the Troubadours. Medieval Occitan society, c. 1100-c. 1300, Cambridge, University Press, 1993, p. 81, qui nie que ce rite représente déjà une sorte d'ordination permettant d'entrer en chevalerie.

68. Nombreuses mentions d'armes dans les testaments et cessions en gage de Toulouse, J. H. Mundy, Liberty, op. cit. (n. 4), p. 230-231, n. 50, et p. 356-357, n. 52. Sur la traditio cum equis et armis, cf. E. Delaruelle, \& Templiers et Hospitaliers en Languedoc pendant la croisade des Albigeois », Cahiers de Fanjeaux, 4 (1969), p. 233-234. De nombreuses armes apparaissent dans le procès-verbal du complot de Nîmes de 1210, L. Ménard, Histoire civile, op. cit. (n. 18), PJ 39, p. 48-52.

69. F. Valls Taberner, Los Usatges, op. cit. (n. 67), p. 76, $n^{\circ} 9$.

70. Les critiques formulées, en particulier par Lucien Febvre, sur l'emploi du mot * patriciat *, disqualifié pour son anachronisme, ont été rejetées avec justesse par plusieurs médiévistes, dont S. Bensch (Barcelona, op. cit. (n. 4), p. 174-175). Des Patricii apparaissent à Bruxelles en 1303. Après tout, nous participons bien à un colloque sur les * élites urbaines », expression qui n'a rien de médiévale.

71. Sur l' expeditio pedestris des bourgeois toulousains, dont certains combattent, cependant, à cheval au cours de la croisade albigeoise, cf. P. Wolff, $\star$ La noblesse toulousaine : essai sur son histoire médiévale », dans P. Contamine (sous la direction de), La noblesse au Moyen Age. Essais da la mémoire de Robert Boutruche, Paris, PUF, 1976, p. 165-167. Cf. L. M. Paterson, The World, op. cit. (n. 67), p. 48-49, qui analyse l'activité militaire, jamais montée, des bourgeois dans les textes litteraires, notamment dans La chanson de la croisade albigeoise. L'évêque de Béziers peut exiger de tous les burgenses qu'ils le suivent in expeditione à l'interieur de son diocèse, $C$. Duhamel-Amado, La famille, op. cit. (n. 34), t. 1, p. 288. 
La distinction entre ceux qui combattent à cheval ou a pied est-elle fixé pour toujours dans la rigidité d'une taxinomie sociale contraignante ? Quelle est l'attitude des chevaliers à l'égard de l'un de leurs concitoyens qui, sans être le fils d'un miles, ose se rendre a l'ost comme cavalier ? Veillent-ils jalousement à la fermeture de leur caste guerrière, l'excluant sans égards, ou l'acceptent-ils volontiers, s'il en a les capacités et l'entraînement, parce qu'il renforce leur troupe ? Seules les sources littéraires nous renseignent sur ce point. Les chevaliers de Girart de Roussillon, poème épique rédigé dans le Midi entre 1135 et 1180 , refusent de prendre des fils de paysans dans leurs rangs $72:$ la fiction litteraire témoigne ici d'une conscience généalogique fort poussée à l'encontre des rustres. Mais encore faut-il savoir si ce sentiment de rejet est profondément enracine dans l'esprit du guerrier professionnel qui ecoute cette chanson, surtout si les impetrants à la cavalerie sont issus du patriciat des villes. Un premier mouvement d'hostilité contre les nouveaux venus paraît, certes, naturel au sein d'un groupe attaché au pouvoir et au prestige que lui accorde l'exercice de la violence.

Mais la fluidité des élites urbaines, prêtes à de multiples brassages, est une constante de notre période. Rien n'empêche un propriétaire foncier, enrichi par la vente des produits de ses terres, ou un marchand, ayant réussi une belle affaire commerciale, de vivre de rentes a l'instar des chevaliers qu'ils fréquentent en ville et dont ils adoptent le genre de vie. Leurs enfants tenteront de se procurer une monture, d'apprendre à combattre à cheval, de devenir les fideles d'un seigneur et d'épouser une fille de l'aristocratie. S'ils y parviennent, ils intégreront le groupe des milites. Lorsqu'il s'agit de déterminer les véritables contours de la chevalerie urbaine, cette mobilité sociale brouille maintes pistes. Pour connaître le rang et le rôle des guerriers citadins, pour cerner ce qui les unit aux autres catégories urbaines et ce qui les en sépare, force est de passer en revue le vocabulaire qui les désigne, leurs prérogatives juridiques et leur milieu familial.

\section{Vocabulaire : qualificatifs d'une catégorie}

Aux XI e et XIIe siècles, les scribes accolent souvent une épithète honorifique aux individus ou aux groupes dont ils consignent le nom dans une charte. Pour qualifier le chevalier occitan, ils se servent alors de miles ou de cabalarius, qui se traduisent, tous deux, dans la poésie des troubadours, par cavalier, voire, en langue d'oil dans les textes, par chevaler 73 . Le prestige de cette dénomination transparaît dans un acte, dressé en 1119 à Carcassonne, qui établit la différence

72. L. M. Paterson, The World, op. cit. (n. 67), p. 86. La chanson de Girart de Roussillon, 6d. M. de Combaricu, G. Gouiran, Paris, Le Livre de Poche, 1993 (Lettres Gothiques).

73. G. Duby, « La diffusion du titre chevaleresque sur le versant méditerranéen de la Chrétienté latine $»$, dans $P$. Contamine (sous la direction de), La noblesse, op. cit. (n. 71), p. 39-70 ; J.P. Poly, La Provence, op. cit. (n. 4), p. 136-141 ; L. M. Paterson, The World, op. cit. (n. 67), p. 65. 
entre deux plebes, la «militaire» ou chevaleresque, d'une part, et la « populaire», de l'autre (tam militaris quam popularis plebis) 74 : cette bipartition corrobore la place prépondérante que les milites occupent au sommet de la société urbaine, au-dessus des autres laïcs. On peut pareillement les appeler « très honorables », « illustres » ou « nobles », qualificatifs dont la connotation est aussi morale que sociale, contrairement à miles ou cabalarius qui renvoient surtout au metier des armes 75. Le chevalier apparaît parfois comme « seigneur » (senior, dominus), en particulier s'il exerce un pouvoir de contrainte sur les habitants d'un quartier urbain ou sur les paysans d'un domaine rural 76 . Plusieurs substantifs et adjectifs spécifiques nomment donc le membre de la chevalerie urbaine.

Ils entrent parfois dans le champ sémantique de probus homo, expression dont la signification sociale est complexe. En theorie, le «prud'homme » est le membre des élites dirigeantes d'une ville qui n'appartient pas à la chevalerie 77 : les milites siègent presque toujours séparément des probi homines dans le conseil municipal, où chacune de ces deux catégories dispose d'un nombre de sièges égal 78. Mais, dans la pratique, les différences entre les uns et les autres, tous membres à part entière du même patriciat urbain, sont des plus ténues 79 . A

74. HGL, t. 5, col. $881, \mathrm{n}^{\circ} 469$ (1119).

75. Le procès-verbal de l'assemblée tenue à Narbonne le 7 mai 1080 retranche les honestissimi, centuriones, illustres viri, nobiles, milites et seniores du groupe des cives Narbonenses, HGL, t. 5, col. 656-658, $n^{\circ} 339$. « Noble $n^{\prime}$ est pas toujours employé au sens stricte de membre d'un lignage aristocratique : en 1198, un acte est passé « devant les nobles hommes du chapitre * de Toulouse (ante presenciam nobilium virorum capituli), qui comprend des chanoines issus de familles autres que nobiliaires, J. H. Mundy, Liberty, op. cit. (n. 4), p. 202-203, n $^{\circ}$ (15 XII 1198).

76. M. Aurell, Une famille, op. cit. (n. 39), p. 31-34 ; J. H. Mundy, Liberty, op. cit. (n. 4), p. $357, n$. 53. Une reconnaissance explicite du ban des chevaliers de Montpellier apparaît dans un acte du 24 janvier 1104 : Hec omnia vobis dono, preter districta et firmantias militum Montispessulani et uxorum eorum, A. Germain-Martel, Liber, op. cit. (n. 32), p. 207, n 100.

77. Et multorum civium, tam militum quam proborum hominum, J.-H. Albanès, U. Chevalier, Gallia christiana novissima, Valence, 1920, t. 7 (Avignon), $\mathrm{n}^{\circ} 245$ (v. 1129); militum ac proborum hominum et civium Narbonensium, A.N., J 314, Toulouse, 7, $\mathrm{n}^{\circ} 10$ (III 1204), cité par J. Caille, « Le consulat de Narbonne. Problème des origines \#, dans Les origines des Libertés urbaines, Rouen, Publications de l'Université de Rouen, 1990, p. 261, n. 67 ; consilio proborum hominum civitatis et militum castri, L. Ménard, Histoire civile, op. cit. (n. 18), PJ 26, p. $37-38$ (6 VI 1161).

78. Soixante et soixante respectivement, sur les cent vingt sièges du consilium d'Arles, $L$. Stouff, « La commune », op. cit. (n. 12), p. 305.

79. * Parmi les prud'hommes, il y a des nobles : chevaliers descendants de vieilles familles fixées ici dès l'époque carolingienne *, P. Wolff, « L'essor urbain », dans Histoire de Toulouse, Toulouse, Privat, 1974, p. 72 ; * Entre la classe des prud' hommes et celle des chevaliers la différence était peu marquée dans le Midi », V.-L. Bourrilly, Essai, op. cit. (n. 31), p. 25 ; « Considérer ces deux groupes [milites et probi homines] comme des classes serait s'en tenir à une conception juridique de l'histoire $\star$, L. Stouff, « La commune $\star$, op. cit. (n. 12), p. 305, reprenant une 
Moissac, une charte du début du XIIe siècle met parmi les prosomes des moines, des chevaliers et des bourgeois, tandis qu'à l'Isle-Jourdain, en 1190, on énumère miles, burgensis et alius probus homo ${ }^{80}$. Voici un exemple plus concluant encore sur cet amalgame : a Avignon, Pons de Codolet (1191-1224), Rostaing de Pargues (1192-1223) et Peire Féraud (1219-1228) sont, au fil des années, élus indifferemment consuls en tant que chevaliers ou en tant que prud'hommes 81. Ces hesitations des scribes et ces flottements statutaires montrent que la frontière entre les deux catégories est aisément franchissable.

Miles apparaît, en outre, dans les chartes en opposition avec civis, « citoyen », et burgensis, « bourgeois » 82 . Ces deux derniers termes sont habituellement synonymes, quoique dans quelques villes ils puissent marquer la distinction topographique entre les habitants de la Cité, d'une part, et ceux du Bourg, de l'autre 83 . Ils désignent, comme probus homo, les citadins privilégiés qui participent au gouvernement municipal avec les chevaliers ${ }^{84}$. Mais, comme les « prud'hommes », les « citoyens » 85 , et peut-être les « bourgeois » 86 , sont

conclusion d'E. Engelmann, Zur städtischen Volksbewegung in Südfrankreich Kommunefreiheit und Gesellschaft. Arles (1200-1250), Berlin, 1959.

80. L. M. Paterson, The World, op. cit. (n. 67), p. 154.

81. J.-P. Poly, « De la citadelle », op. cit. (n. 22), p. 117-118.

82. Alii cives ac milites, HGL, t. 5 , col. $656-658, \mathrm{n}^{\circ} 339(7 \mathrm{~V} \mathrm{1080})$; in presencia tam militum quam burgensium, L. Ménard, Histoire civile, op. cit. (n. 18), PJ 26, p. $37-38$ (6 VI 1161); tam milites quam civites utriusque civitatis [Nîmes et Arles], tam majores quam minores, ibid., PJ 40, p. 52-53 (11 VII 1213). Pour la différence entre nobiles et burgenses, cf. l'acte analysé par G. Duby, « Les seigneurs et la cité (Embrun-1177) », Provence historique, 23 (1973), p. 94-98.

83 Oblii qui invicem debentur civibus et burgensibus. Cives enim contradicebant burgensibus oblias, quas eis debebant non illas eis debere deferre in burgo. Burgenses siquidem contradicebant oblias, quas eis debebant non illas eis debere deferre in urbe, R. Limouzin-Lamothe, La commune, op. cit. (n. 55), p. 288-289, $\mathrm{n}^{\circ} 15$ ((V 1184); rogatu omnium tam civium quam burgensium Albiensium, HGL, t. 5, col. 414, $n^{\circ} 174$ (1035); nos homines Barchinonenses cives et suburbani, J. M. Font Rius, Origenes del régimen municipal de Cataluña, Madrid, 1946, p. 469 471, PJ 2 (11 VI 1100). Cf. A. Dupont, Les cités, op. cit. (n. 5), p. 662-664.

84. Certaines formules montrent qu'ils sont au-dessus des autres habitants de leur ville : $m i$ lites, burgenses et universus alius populus et suburbani, HGL, t. 5, col. 804, n 347 (1107).

85. Consilio et assensu consulum qui tunc Avinioni civitati prarant et multorum civium, tam militum quam proborum hominum, Gallia christiana, op. cit. (n. 77), t. 7, n 245 (v. 1129).

86. La totalité de la population d'une commune (commune), englobant les milites, est désignée, de façon indifférente, par cives pour Marseille et Nîmes ou par burgenses pour Saint-Gilles et pour Montpellier, dans l'acte d'octobre 1187, par lequel Conrad de Montferrat leur accorde des privilèges commerciaux dans la ville de Tyr, V.-L. Bourrilly, Essai, op. cit. (n. 31), p. 29. En 1148, Raimond Bérenger IV (1131-1162) cède en gage les moulins de Tortosa vobis burgensibus Barchinona magnis et parvis, cité par Font Rius, Origenes, op. cit. (n. 83), p. 137-138, n. 352 : il est vraisemblable que des chevaliers figurent parmi ces magni burgenses se partageant les profits d'une ville récemment conquise aux musulmans. Expression équivalente (majores et minores burgenses) dans une bulle accordée par Calixte II (1119-1124) à Saint-Gilles, citée par A. Dupont, Les cités, op. cit. (n. 5), p. 663. Il est vrai, pourtant, que la différence entre \& majeurs $»$ et 
quelquefois des « chevaliers ». La difficulté qu'éprouvent les scribes de l'epoque pour établir une hiérarchie précise au sein du patriciat est manifeste.

Leurs fluctuations sémantiques montrent, en définitive, combien il leur en côte d'avoir toujours présent à l'esprit la différence entre les membres de la chevalerie urbaine et de la bourgeoisie. Il en va de même pour tous leurs concitoyens, qui ont parfois du mal a apprehender le statut social de tel ou tel notable et a faire la part respective de ceux que les sources appellent les milites, les probi homines, les cives et les burgenses. Des distinctions reposant exclusivement sur la fonction militaire, sur la fortune foncière ou monetaire et sur le genre dé vie n'assurent pas une division rigide et permanente parmi les élites citadines 87 .

\section{Législation : privilèges et interdits}

Une étude des textes législatifs confirme cette proximité des milites et des autres patriciens. Les Usages de Barcelone sont, à ce sujet, assez explicites. Leur article 10 applique aux citoyens et aux chevaliers la même procédure judiciaire, les mêmes amendes et les mêmes compensations pécuniaires qu' aux bourgeois 88 ; l'article 56 accorde à la parole assermenté d'un chevalier le même crédit qu'à celle d'un bourgeois : il ordonne toutefois que ce dernier se batte à pied dans le duel judiciaire, cependant que le miles le fait à cheval 89 ; l'article 69 prévoit que les successions ab intestat des chevaliers et des bourgeois soient expropriées de la même façon 90 . A lire ces lois, la qualité sociale du miles et du civis ou burgensis ne differe guère.

Force est, toutefois, de reconnaître que les Usages attribuent ailleurs une legère supériorité aux chevaliers qui sont exemptés du prélèvement par le comte du tiers de l'indemnisation qu'eux ou leurs parents auraient reçue pour blessure

\footnotetext{
« mineurs » pourrait concerner des bourgeois au sens strict, groupe indépendant de la chevalerie : au milieu du XIII e siècle, la bourgeoisie de Barcelone, qui exclue les chevaliers du conseil municipal, est divisée en trois « mains » (majeure, moyenne et mineure).

87. * The line between the knights and other social groups were therefore very confused *, J. H. Mundy, Liberty, op. cit. (n. 4), p. 11.

88. Cives autem et burgenses sint inter se judicati, placitati atque emendati sicut milites, $F$. Valls Taberner, Los Usatges, op. cit. (n. 67), p. 76.

89. Sacramenta burgensium credantur ut militum usque ad quinque uncias auri. Deinde, quidquid jurent per bellum deffendant, scilicet de pedone, ibid., p. 86.

90. Ut exorquie nobilium videlicet et magnatum, tam militum quam burgencium, omni tempore in principum potestate deveniant, ibid., p. 91.
} 
ou meurtre 91 . Une gradation similaire transparait dans la procédure que doit engager l'épouse accusee d'adultère pour prouver son innocence : la femme du chevalier se soumet au serment purgatoire et son champion s'acquitte du duel judiciaire à cheval ; celui de la bourgeoise se bat à pied ; la paysanne doit subir elle-même l'ordalie à l'eau bouillante 92 . Ces dispositions judiciaires sont comparables à la loi, édictée en 1174 par l'évêque de Vic, punissant les «prud'hommes » et les «puissants» qui utilisent une autre monnaie que la sienne sur son marche a une amende de dix sous, contre cinq sous pour les « médiocres » et contre deux sous et des peines corporelles pour les « mineurs » et « vilains » 93. Il ressort de ces textes que le législateur considère que le statut du chevalier est presque identique à celui du bourgeois, a la seule différence près que l'un combat en cavalier et l'autre en piéton 94.

Les comtes et les seigneurs des villes gratifient les milites de quelques exemptions de redevances. Les chevaliers ne doivent pas de droit de gîte (alberga, hospitium), la taxe d'origine régalienne due pour l'hébergement du seigneur et de sa troupe 95 ; a Arles, leurs maisons partagent cette immunité avec les « ateliers des marchands $\$ 96$, ce qui rapproche, une fois de plus, ces deux catégories sociales. Dans cette même ville, les milites ne versent pas au comte ou à l'archevêque de pacage pour leurs troupeaux de la Crau, ni de taxe pour leurs marchandises quand ils empruntent le bac pour traverser le Rhône. Is ne doivent pas de droit sur le sel : c'est pourquoi ils montent sur les bateaux étrangers pour soutirer leur exemption des agents préposés au péage, façon de

91. De omnibus hominibus, exceptis militibus, scilicet de burgensibus et bajulis atque rusticis, constituerunt sepedicti principes haberi de esmenda terciam partem seniores eorum, ibid., p. 102. art. 102.

92. Uxores militum per sacramentum et insuper per militem; uxores civium et burgensium et nobilium bajulorum per pedonem; et uxares rusticorum manibus propriis per calderiam, ibid., p. 105, art. 112.

93. Donet pro iustitia $X$ solidos, si probus homus [sic] est, et potens, si vero mediocris est donet $V$ solidos, cité par J: M. Font Rius, Ortgenes, op. cit. (n. 83), p. 144, n. 369. Autour de 1041 1075, dans le village de Sanahuja, l'évêque d'Urgell exempte de corvée de construction et de charroi les prêtres, les chevaliers, les bailes et les marchands, P. Bonnassie, La Catalogne, op. cit. (n. 43), p. 854.

94. Dans son étude de ces articles des Usages, J. M. Font Rius [Origenes, op. cit. (n. 83), p. 139] conclue : * No obstante esta indecision, puede colegirse que los ciudadanos formaban una clase especial y con evidente situación privilegiada que - por lo menos-les acercaba, si no los igualaba, a la de los milites o caballeros, la nobleza inferior. "

95. Et vicarius, vel alius pro eo, mandabit alberguos in toto Montepessulano, preter albergos militum, A. Germain-Martel, Liber, op. cit. (n. 32), p. 208, n 100 (24 I 1104). I existe, pourtant, des exceptions à cette immunité pour les chevaliers et leurs familles : C. Duhamel-Amado, La famille, op. cit. (n. 34), t. 1, p. 286 ; A.R. Lewis, Medieval Society, op. cit. (n. 14), I, p. 573.

96. exceptis domibus militum et operatoriis mercatorum, ed. E. Smyrl, $\propto$ La famille des Baux », Cahiers du Centre d'Etudes des Sociétés Méditerranéennes, 2 (1968), p. 83, PJ 10 (IX 1150). 
procéder que l'archevêque leur reproche amèrement 97 . S'ils possèdent des terres au nom d'un établissement ecclésiastique, ils n'en sont redevables que pour la seule dîme ${ }^{98}$. Sur le plan fiscal, la situation des chevaliers est enviable.

Ils jouissent, par ailleurs, d'autres privilèges plus symboliques que pécuniaires, les écartant du commun et rehaussant leur prestige. A Toulouse, quelle que soit leur paroisse, ils peuvent demander à être inhumés, avec leur femme et leurs enfants, dans le cimetière de Saint-Sernin où reposent les comtes et les évêques 99 . Recherchent-ils à se distinguer des autres citadins autant dans l'amour que dans la mort ? Un acte de 1113 semblerait leur préserver une endogamie sociale stricte : il s'agit de la renonciation en faveur de Guilhem V $(† 1121)$ d'une partie des droits qu'Almodis, fille de Faidit, un bourgeois du seigneur de Montpellier, détient dans les paroisses de Saint-Firmin et de SaintDenis de Montpellieret ; cette femme a épouse Guilhem Aimon, chevalier, fils du vicaire seigneurial ; or, Guilhem V récupère ses biens sous prétexte de la coutume qui existe a Montpellier depuis le temps de son grand-pere, interdisant « a un quelconque bourgeois de céder son patrimoine, ni de le vendre, ni de l'hypothequer à un chevalier, a un religieux ou à un clerc, ni de donner sa fille pour épouse à un chevalier avec le patrimoine qu'il aurait a Montpellier et dans toute la paroisse de Saint-Firmin $100 »$. En dépit des apparences, ce document traduit davantage l'existence d'échanges matrimoniaux entre les chevaliers et les bourgeois que leur impossibilite juridique : Guilhem $V$ ne peut ni ne veut les empêcher, mais prend prétexte d'une coutume, peu efficace sans doute, pour exproprier le patrimoine de Faidit afin que les Aimon n'en héritent pas. Son calcul ne manque pas de clairvoyance politique, comme le prouve la révolte que les membres de cette maison de chevaliers, ses propres parents et vicaires, forts de leur fortune et de leur puissance, fomentent en 1141.

Pour preuve de la proximité de la chevalerie et de la bourgeoisie, retenons que ces milites investissent une partie des profits de leurs fiefs dans des activites marchandes. La chevalerie d'Arles, qui contrôle les salins de Camargue, fait du

97. J.-P. Poly, La Provence, op. cit. (n. 4), p. 302-303.

98. Exemption de champart d'interprétation difficile dans un acte du monastère de SaintCésaire d'Arles : quisquis possidebat terram si miles est dat decimam, si alius agricultor tascam et decimam, A.D. Bouches-du-Rhône, 60 H 24, n 4 (1205).

99. Ut episcopus et comes et milites omnes et eorum uxores, filii quoque et filie, sine contradictione vel calumpnia mortalium aliquorum, in cimiterio Sancti Saturnini, ab hac ora in perpetuum sepeliantur, C. Douais, Cartulaire de Saint-Sernin de Toulouse, Paris-Toulouse, 1887, p. 4, $n^{\circ} 2$ (2 XII 1093).

100. quod alicui burgensi non liceat honorem suum aliqua occasione dare, nec vendere, nec impignorare militi, vel sancto, vel clerico, nec filiam suam liceat in uxorem dare militi cum honore Montispessulani, nec tocius parrochie Sancti Fimini, A. Germain-Martel, Liber, op. cit. (n. 32 ), p. 260, n 127 (5 IX 1113). 
commerce du sel le long du Rhône 101. A Toulouse, des lignages de guerriers réussissent brillamment dans leurs affaires. C'est le cas de Bernard de Capdenier $(\dagger 1198)$, dont la famille est originaire d'un hameau suburbain situé au nord du Bourg ; les profits qu'il tire de la commercialisation de ses produits agricoles sur les marchés urbains lui servent à acheter de nombreuses terres en ville. La richesse de son fils Pons ( $†$ 1229), qui vend son bétail et ses grains, qui pratique le prêt sur gages et qui achète et construit de nombreux immeubles, est immense 102. Son testament montre pourtant son attachement au genre de vie chevaleresque : il y confie notamment son écuyer à son gendre Roger Barravi pour qu'il le maintienne à ses frais. Il n'y a nullement d'incompatibilité entre la chevalerie et les affaires. Les Sigar sont des nobles de Béziers attestés depuis le $\mathrm{X}^{\mathrm{e}}$ siecle, apparentés aux grandes familles princières du Languedoc et amis des Trencavel ; or, Peire Sigar (1180-1206) apparaft dans les chartes biterroises en tant que «négociant » (negociator) et « marchand» (mercator), alors que Guilhem Sigar est cité, en mai 1204, comme bourgeois de Béziers 103. Leurs terres, péages et taxes accordent aux guerriers les capitaux nécessaires pour s'adonner au commerce. Personnellement ou par agents interposés, ils prati quent le négoce. Les mentalités communes ne répugnent pas encore de les voir spéculer dans l'immobilier, écouler leur blé et leur viande sur le marché urbain ou vendre leur sel aux marchands italiens. En cela, rien ne différencie les milites de ceux que les actes appellent probi homines, cives ou burgenses, membres à part entière du même patriciat urbain 104.

\section{Origines : aristocrates et alleutiers}

La chevalerie urbaine est hétérogène. Les origines des familles qui la composent sont multiples. Aux XIe et XII e siecles, les statuts des personnes apparaissent encore faiblement marqués en ville, où les membres de la très vieille aristocratie, carolingienne et même sénatoriale, retrouvent des hommes nouveaux dans l'exercice commun du métier des armes à cheval.

101. Raimond Sacristain de Porcelet et d'autres milites participent même, en 1113, à l'expédition catalane contre Majorque avec leurs propres navires, qui leur servent habituellement pour des activités lucratives, M. Aurell, Une famille, op. cit. (n. 39), p. 35.

102. «Poncius was the Croesus of late twelfth and early thirteenth century Toulouse », J. H. Mundy, Liberty, op. cit. (n. 4), p. 62.

103. C. Duhamel-Amado, « Pouvoir épiscopal et communauté urbaine au XIIe siècle », dans F. Thelamon (sous la direction de), Sociabilité, pouvoirs et société, Rouen, Publications de l'Université, 1987, p. 350-351.

104. L'incapacité de la chevalerie urbaine à affirmer sa spécificité juridique au début du XIIe siècle est soutenue par S. Bensch, Barcelona, op. cit. (n. 4), p. $146:$ * Urban knights did non emerge from the early twelfth century as a well-defined or assertive group in Barcelona. * 
A l'aide d'une methode prosopographique rigoureuse, les historiens remontent jusqu'a la souche de certaines de ces lignées chevaleresques. Une thèse récente vient de démontrer l'ancienneté de la plupart des grandes familles biterroises de l'entourage de l'évêque et du vicomte. Leurs membres, issus de l'aristocratie carolingienne, détiennent les castra ceinturant Béziers dans un rayon d'une vingtaine de kilometres : ils prennent, en effet, leur nom des villages fortifiés de Sauvian, de Sérignan, de Villeneuve, de Cers, de Corneilhan, de Thézan ou de Maureilhan dont ils sont les seigneurs ; ils ont un pied a la ville et l'autre à la campagne 105. Une situation similaire se retrouve à Nîmes, où les Langlade, Vézénobre, La Calmette, Clarensac, Aubais ou Aramon demeurent dans les Arènes 106 ; leur maison a été fondée par des cadets qui, à l'étroit dans le domaine ancestral, preferent tenter leur chance dans la cite voisine, se mettant au service des grands laïcs et ecclésiastiques 107. Parce qu'elles concentrent l'essentiel de la fortune familiale dans les mains de l'aîne, les structures lignagères poussent maints jeunes a tenter leur chance en quittant les leurs. La perception de cet exode rural d'élite et de cette mainmise de la noblesse campagnarde sur les cités renverse la vision traditionnelle des médiévistes qui insistaient naguère sur le triomphe de la ville conquérante sur son arrière-pays transformé en contado.

La présence d'aristocrates issus des campagnes est aussi marquée a Barcelone. Les Queralt, Alemany, Lluçà, Cervello, Rubf, Montcada ou Mediona, originaires des châteaux des collines environnantes, possèdent une maison forte en ville 108. Il en va de même avec les Castellvell. Documenté en 938, Sendred, premier ancêtre connu de cette famille, est l'un des viguiers aux quels le comte de Barcelone confie la garde de plusieurs châteaux de la frontière méridionale de sa principauté secouée par les raids musulmans. En 1023, le comte Bérenger Raimond Ier (1017-1035) vend la forteresse de Castellvell de la Marca a Guillem, descendant de Sendred ; les Castellvell entrent, en outre, en possession du château de Rosanes, à côté duquel ils bâtissent le monastère de Sant Genís devenu leur nécropole. Tous ces biens se trouvent dans l'arrièrepays de la cité comtale. En 1110, Raimond Berrenger III (1076-1131) n'installe pas moins quelques membres de ce lignage dans la porte de Castellvell de Barcelone, qu'il vient de reprendre aux vicomtes à la fídélité défaillante. Cette

105. C. Duhamel-Amado, La famille, op. cit. (n. 34), t. 1, p. 194, et t. 2, p. $427-480$ et 493. Contrairement à l'usage courant, $C$. Duhamel-Amado applique le terme $*$ alleu $*$ aux propriétes foncières aristocratiques, bien plus nombreuses et importantes dans le Biterrois de l'an mil que les terres contrôlées directement par les paysans : cf. son article $*$ L'alleu paysan a-t-il existé en France méridionale autour de l'an mil ? , dans $\mathbf{R}$. Delort (sous la direction de), La France de l'an Mil, Paris, Seuil, 1990, p. 142-161.

106 R. Michel, « Les chevaliers », op. cit. (n. 11), p. 48.

107. A. Dupont, Les cités, op. cit. (n. 5), p. 667-668 et 681 .

108 . S. Bensch, Barcelona, op. cit. (n. 4), p. 135-140, et J. C. Shideler, A Medieval Catalan Noble Family: The Montcadas, 1000-1230, Berkeley, University of California Press, 1983. 
famille acquiert alors une maison sur l'enceinte romaine de la ville ${ }^{109}$. Au service du comte, elle s'implique davantage dans les affaires urbaines.

Ces lignées rurales happées par la ville n'appartiennent cependant pas tou jours à la vieille aristocratie. La richesse des sources du comté de Barcelone permet de pénétrer le monde grouillant d'une paysannerie en armes tentée par l'aventure urbaine. Vers 1100 , le testament de Bonadona, veuve d'un agricul teur de l'arrière-pays de cette ville, révele une famille de fortune moyenne ; cette femme est, en effet, contrainte de vendre un muids de terre pour quatre mancus d'or afin de procéder à des aumônes en faveur des églises et des monastères urbains ; elle lègue, toutefois, à Pere Balluvin, son neveu, un haubert et le harnais et la selle d'un cheval 110. Les Vivas de Provençals appartiennent à la même paysannerie libre, entreprenante et armée des environs de Barcelone. Llorenç ( $†$ 987), fondateur de cette famille, cultive ses propres alleux, éleve son troupeau et combat les musulmans ; Vivas, son aîne, parvient à acheter un quart de la turris blanca, le château de Provençals ; ses jardins irrigués et ses vignes lui procurent des produits qu'il commercialise, avec grand profit, sur le marché de la ville voisine. L'intégration de cette maison dans le haut patriciat barcelonais est acquise à la troisième génération : Pere, fils de Vivas, épouse Guisla, nièce de l'écolâtre de Barcelone, fait son pèlerinage à Jérusalem et siège, en 1040, parmi les notables (proceres) d'un tribunal présidé par l'évêque de Gérone pour régler le différend entre Guislabert, évêque de Barcelone, et Eliarda, châtelaine de Cervello ; il a ses entrées au palais comtal. Ainsi, les Vivas, issus du milieu des cultivateurs aisés des alentours de Barcelone, intègrent la chevalerie de cette ville. La gestion avisée de leur patrimoine, dont la primogéniture et l'indivision empêchent la dispersion, explique leur promotion 111 .

Cette mobilité n'est pas exclusive à la seule Barcelone, ville frontalière dont les plus osés des habitants s'enrichissent du butin de la guerre menée contre les musulmans. La plupart des spécialistes constatent une fluidite identique dans la société des autres villes occitanes. En Provence, les chartes mentionnent les alodarii ou « alleutiers », catégorie de paysans qui possèdent leurs terres en nue propriété, de laquelle émergent maints notables urbains ${ }^{112}$. Il se pourrait même

109. B. Garí, El linaje de los Castellvell en los siglos XI y XII, Bellaterra (Barcelone), Publicacions de la Universitat, 1985.

110. S. Bensch, Barcelona, op. cit. (n. 4), p. 142.

111. P. Bonnassie, * Une famille de la campagne barcelonaise et ses activités économiques aux alentours de l'an mil », Annales du Midi, 86 (1964), p. 261-303.

112. $*$ Les actes nous montrent parfois, à la fin du $\mathrm{IX}^{\mathrm{e}}$ siècle, l'existence d'une classe médiane, intermédiaire entre la noblesse et la paysannerie asservie, formée de petits propriétaires plus tard appelés "alleutiers", et divisée en fait en deux couches, les notables, qui vivent en ville, et ceux qui demeurent en campagne, les manants », J.-P. Poly, «L'autre nom du comte Raimon », dans La Catalogne et la France méridionale autour de l'an mil, Barcelone, Generalitat de Cata- 
que quelques-uns des petits chevaliers toulousains, notamment parmi les vavasseurs, couche inférieure des feudataires, proviennent de la servitude, à savoir du milieu des paysans qui dépendent entièrement, dans leur corps et dans leurs biens, d'un seigneur 113. Le monde urbain facilite d'autant plus ces brassages que les nobles eux-mêmes y pratiquent les activités marchandes sans interdit aucun. Les frontières entre les différents groupes qui composent les élites citadines sont presque inexistantes : le train de vie et les modeles culturels de la chevalerie sont adoptés par les paysans enrichis qui s'adonnent à la guerre en combattant à cheval.

Il est, néanmoins, indéniable que la plupart des lignages militaires des cités méridionales ont de vieilles racines nobiliaires. Les études les plus récentes tendent à le prouver. Pourtant, l'arbre généalogique ne saurait cacher la forêt de l'analyse des élites dans toute leur hétérogénéité, leur diversité et leur fluidité. La société urbaine de l'an mil ne se caractérise pas par son immobilisme, mais par sa fluidité. La chevalerie d'origine aristocratique est irrigué du sang neuf que lui apporte le groupe des alleutiers. Certaines chartes se font même l'écho de la dichotomie qui s'instaure, pour quelques génerations encore, au sein de ce groupe entre les anciens et les nouveaux. Sans doute explique-t-elle la séparation des chevaliers entre « majeurs » et « mineurs», établie par le scribe des actes du concile de Saint-Gilles de 1056114 ? L'ouverture du groupe des guerriers est alors indéniable.

La fermeture et, surtout, la fixation des statuts n'intervient que dans le courant du XIIIe siècle. A l'époque, le groupe des guerriers des villes, qui se définissait en premier lieu par le métier des armes et par le genre de vie, devient une véritable noblesse, une catégorie juridique héréditaire dotée de privilèges entérinés par la royauté. On passe alors « de la classe de fait à la noblesse de

lunya, 1991, p. 83. Sur * l'évolution qui conduisit bien des alleutiers campagnards dans les rangs de la chevalerie $»$, cf. du même auteur, La Provence, op. cit. (n. 4), p. 286. Il est assurément exagéré de faire descendre de ce milieu tous les chevaliers urbains : * Primitivement, les milites étaient les hommes libres adonnés au métier des armes que les comtes ou leurs représentants avaient établis ou qu'ils avaient obligés à résider au moins quelques mois par an dans la ville pour la défendre contre leurs ennemis. », H.-L. Labande, Avignon au XIIIe siècle. L'évêque Zoen Tencarari et les Avignonnais, Paris, 1908, p. 172.

113. « Some of these vavassors or lesser knights were even serviles in the eleventh century \#, J. H. Mundy, Liberty, op. cit. (n. 4), p. 11. Au XIIIe siècle, les possibilités d'ascension existent encore à Toulouse : « La noblesse urbaine, d'ailleurs, ne dut être en aucune façon une classe fermée et l'acquisition par les bourgeois de fiefs nobles dans la ville, maison ou enclos (domus, honor, casale), dut suffire à leur conférer la noblesse. $», R$. Limouzin-Lamothe, La commune, op. cit. (n. 55), p. 228.

114. Militibus autem majoribus vel minoribus, P. Labbe, G. Cossart, Sacrosancta concilia ad regiam editionem exacta, Paris, 1671-1672, t. 12, p. 11. Cf. M. Aurell, Une famille, op. cit. (n. 39), p. 32-34 
droit $115 »$, de l' « aristocratie a la noblesse 116 » ou de la « puissance aux privilèges 117 ». Cette transformation capitale du groupe aristocratique coïncide avec la concrétisation de la bourgeoisie en un ordre ou un état : a Arles, à partir de 1274 , la distinction entre le « noble " et le «bourgeois » (nobilis et burgensis) remplace l'ancien binôme " chevalier » ou «prud'homme» (miles et probus homo) dans les épithètes honorifiques des chartes 118 . La noblesse et la bourgeoisie, parfaitement constituées sur le plan du droit, ne peuvent plus se confondre. A la fin du XIIIe siècle, les statuts des personnes sont clairs, et le passage d'un individu d'une catégorie juridique à l'autre, s'il n'est pas impossible, nécessite du moins l'aval de l'administration royale, princière ou commu nale. A Barcelone, la netteté de la définition des états se traduit par l'exclusion des chevaliers du gouvernement municipal : en 1360, la famille Marc, qui descend d'un notaire, se voit par exemple interdire le conseil qui régit la ville à la suite de l'anoblissement de ses membres 119 . Cette rigidité dans la définition du rôle et du rang des personnes tranche fortement sur la période précédente où la mobilité sociale était de mise.

\section{Une culture du pouvoir}

Les chevaliers citadins détiennent une culture propre, aristocratique et urbaine en même temps. Certains de ses membres s'adonnent à des études juridiques approfondies qui les poussent à enserrer dans le cadre institutionnel du consulat la domination qu'ils exercent sur leur ville. Ils acquièrent des connaissances de droit romain dans les chapitres cathedraux où ils deviennent chanoines. Mais leur culture n'est pas seulement ecclésiastique : elle prend une tournure bien profane dans les chansons en oc où ils chantent la dame et la fin'amors. Leur spiritualité est profondément marqué par les nouveaux ordres religieux qui naissent au XII e siecle.

115. M. Bloch, La société féodale, Paris, A. Michel, 1968, p. 445-460.

116. G. Duby, « Situation de la noblesse en France au début du XIIIe siècle », dans Hommes et st ructures du Moyen Age, Paris, Masson, 1973, p. 343-352.

117. P. Contamine, « De la puissance aux privilèges : doléances de la noblesse française envers la monarchie aux XTV et XVe siècles », dans P. Contamine (sous la direction de), La noblesse, op. cit. (n. 71), p. 235-260.

118. L. Stouff, « Nobles et bourgeois dans l'Arles du Bas Moyen Age. Un patriciat? », dans Histoire et société. Melanges offerts a Georges Duby, Aix, Publications de l'Université de Provence, 1992, t. 2, p. 182.

119. C. Batlle, L'expansib baix medieval (segles XIII-XV), Barcelone, Enciclopèdia catalana, 1988, p. 98. 


\section{Consulat : justice et paix}

Depuis la fin de l'Empire romain, leur position dominante accorde, tout naturellement, aux milites une place prépondérante dans l'exercice de la justice en ville. Is sieggent en tant que jurés auprès de juges professionnels dans les tribunaux du comte, du vicomte ou de l'évêque. Ils sont choisis parfois comme arbitres, comme garants ou comme tuteurs par leurs concitoyens. Les chartes utilisent plusieurs expressions, dotées d'une connotation morale, pour désigner ces feudataires de la cour seigneuriale ou ces notables représentant les hommes libres dans les assemblées urbaines : boni viri, qu'on trouve déjà chez Cicéron ou dans le code de Theodose, honesti viri et meliores homines, aux $\mathrm{Xe}^{\mathrm{e}}$ et XIe siècles, et, a partir du XII e siècle, probi homines, « prud'hommes » qu'il faut prendre ici dans son acception strictement judiciaire 120 . Qu'elle soit seigneuriale ou communale, la justice urbaine dépend largement des chevaliers.

Dès le premier tiers du XIIe siècle, ces juges ou élus apparaissent de plus en plus dans les textes sous la dénomination de «consuls » (consules). Ce terme vient du nord de l'Italie, où il est mentionne, pour la première fois, dans une charte de Pise datee de 1081-1085. Il passe plus tard, depuis la péninsule, dans les pays du Bas Rhône et du littoral languedocien. Il apparât à Avignon autour de 1129, à Arles et à Beziers en 1131, à Narbonne en 1132, à Saint-Gilles en 1143, à Nîmes, à Nice et à Tarascon en 1144. Il ne sert à désigner les représentants de la commune de la ville vicomtale de Marseille qu'en 1178. A Barcelone et a Montpellier, des consuls sont cités respectivement en 1130 et en 1141 , mais le mot s'efface ensuite des chartes jusqu'au début du XIIIe siècle 121. A Toulouse, les sources mettent plutôt en scène des « capitulaires » (capitularii).

L'apparition de consuls et de capitulaires dans les sources correspond à une organisation communale plus rigide qu'aux temps des assemblees de boni viri. Des chartes précisant le fonctionnement du consulat sont rédigées autour de 1150122 : elles prévoient l'existence d'un college consulaire d'une douzaine de membres qui assume le pouvoir exécutif, d'un conseil délibérant composé de

120. J. M. Font Rius, Origenes, op. cit. (n. 83), p. 247-279, et, du même auteur, une mise au point plus récente, « La comunitat local o veïnal », Symposium internacional sobre els origens de Catalunya (segles VIII-XI), Barcelone, Reial Academia de Bones Lletres, 1992, t. 1, p. 546-567. Pour le Languedoc, cf. A. Dupont, Les cités, op. cit. (n. 5), p. 533, et E. Magnou-Nortier, La sociéte lä̈que, op. cit. (n. 34), p. 253.

121. A. Gouron, * Diffusion des consulats méridionaux et expansion du droit romain aux XIIe et XIII' siecles $\#, B E C, 121$ (1963), p. 26-76.

122. Une étude sur les chartes de consulat d'Arles et d'Avignon se trouve dans J.-P. Poly, * Les légistes provençaux et la diffusion du droit romain dans le Midi », Mélanges $R$. Aubenas, Montpellier, Faculté de droit et des sciences économiques, 1974, p. 631. 
quelque cent citoyens et d'une assemblée génerale qui est la source theorique de la puissance des consuls 123 (figure 8). Elles sont accompagnees de statuts qui donnent un cadre législatif a la vie municipale. La fonction principale des consuls est de faire appliquer cette loi 124 . Ces magistrats siegent, en conséquence, dans un tribunal qui juge les citoyens de leur ville. Dans quelques cites, en particulier en Provence, ils réussissent à s'emparer de la haute justice et jugent même l'homicide, les blessures ayant entraîné effusion de sang, le vol, le rapt et l'adultere 125. Ailleurs, on fait appel à leur tribunal pour les affaires mi neures de propriété foncière, de coups légers ou d'injures. Jadis les notables déliberaient dans la cour du comte, du vicomte ou de l'évêque, qui conservaient le monopole de la justice urbaine ; avec l'aval de ces seigneurs, ils parviennent désormais à accaparer une partie, voire la totalité, des activités judiciaires de la commune 126.

Cette appropriation collective d'une portion du ban par les milites rappelle une coseigneurie 127. C'est en commun que les chevaliers exercent leur pouvoir

123. P.-C. Timbal, « Les villes de consulat dans le midi de la France. Histoire de leurs institutions administratives et judiciaires $»$, dans Societe Jean Bodin. La ville. Institutions administratives et judiciaires, Bruxelles, 1954, p. 360.

124. Sur les trente-sept premiers articles des statuts d'Arles, vingt-six concernent la justice, $L$. Stouff, * La commune », op. cit. (n. 12), p. 304. Cf. également J.-M. Carbasse, Consulats méridionaux et justice criminelle, thèse de doctorat en droit inédite, Université de Montpellier I, 1974, et * La charte consulaire de Millau (1187) *, dans Libertés locales et vie municipale en Rouergue, Languedoc et Roussillon, Montpellier, Fédération Historique du Languedoc méditerranén et du Roussillon, 1988, p. 139-141. Pourtant, A. Castaldo exclut la justice comme critère de définition du consulat, se fondant sur une interpretation, trop restrictive à notre avis, des exemples de Montpellier, Narbonne et Béziers : « Le tiers même des consulats serait dépourvu de droit de justice *, Le consulat, op. cit. (n. 58), p. 24. Ce point de vue est en contradiction avec ce que l'on sait du fonctionnement de la justice dans la majeure partie des consulats méridionaux.

125. J.-P. Poly, La Provence, op. cit. (n. 4), p. 313. Cette récupération par les consuls des crimes ayant entraîné effusion de sang reste cependant exceptionnelle : Carbasse, Consulats, op. cit. Procès pour adultère devant les consuls de Toulouse intenté contre Babylonia, partie avec un mercenaire brabançon, édité par R. Limouzin-Lamothe, La commune, op. cit. (n. 55), p. 328-330 (III 1176). On conserve les minutes des dépositions, en majorité pour des affaires civiles, des querelles ou des injures, devant les juges de Nîmes en 1217 et 1218 , édités partiellement dans $L$. Ménard, Histoire civile, op. cit. (n. 18), PJ 44, p. 55-63.

126. Plutôt qu' une émanation de l'assemblée populaire des boni viri, c'est comme une * sorte de sécession de la cour féodale, sécession souvent acceptée et sanctionnée par le seigneur * qu'apparaît le consulat pour G. Sautel, « Les villes du Midi méditerranéen au Moyen Age. Aspects économiques et sociaux (IXe-XIIIe s.) », dans Société Jean Bodin. La ville. Institutions économiques et sociales, Bruxelles, 1955, p. 335. * Les probi homines du conseil féodal sont ainsi les ancêtres naturels des consuls $»$, ibid. Par cour ou conseil féodal, il faut ici comprendre les feudataires qui prêtaient le consilium à leur seigneur en siégeant dans son tribunal. Sur le partage des amendes à Nîmes entre le vicaire du vicomte et le consilium proborum hominum civitatis et militum castri, cf. L. Ménard, Histoire civile, op. cit. (n. 18), PJ 26, p. 37-38 (6 VI 1161).

127. Cf. un exemple extrême de cette identification entre le consulat et la coseigneurie, dans H. Chobaut, V. Laval, « Le consulat seigneurial de l'Isle-en-Venaissin (XIIe et XIIIe siècles) », 
de contraindre et de juger les hommes dans le domaine d'application qu'ils ont délimité avec les seigneurs urbains ${ }^{128}$. En outre, ils gèrent collectivement une partie des redevances de la seigneurie banale : leudes et péages, autres droits sur le marché, sur la boucherie ou sur la poissonnerie, moulins et pêcheries appartiennent au consulat qui se trouve sous le contrôle strict de cette oligarchie 129. Leur nouvelle domination se concrétise dans le paysage urbain par l'érection d'une maison consulaire. A Toulouse, ce palais communal se trouve sur le mur sarrasin qui sépare la Cité du Bourg, alors que chacun de ces deux quartiers choisit six consuls pour la commune 130 ; à Nîmes, il occupe le capitole. La maison consulaire, comparable aux forteresses que le comte, le vicomte ou l'évêque détiennent en ville, présente la même fonction symbolique que le château rural, dont les tours manifestent aux paysans le pouvoir banal du seigneur.

Dans un tel contexte, le consulat n'a rien d'une institution démocratique, car il se trouve sous le contrôle direct de la chevalerie urbaine qui en accapare les sièges. Bernard de la Porte Vieille, Peire Aldebert et Bernard Bonnet, trois des quatre premiers consuls connus à Nîmes en 1144, sont sans conteste des milites des Arènes; il y a même de fortes chances que Peire Bertrand Calvin, le quatrième, pour lequel le manque de sources empêche d'identifier la qualité, le soit aussi 131. A Arles, au moins vingt-et-un des vingt-huit consuls des années 11351152 appartiennent au même milieu des lignages chevaleresques 132. Subrogation et cooptation permettent, en effet, de garder les sièges consulaires dans les mêmes familles lors de l'élection annuelle : c'est sans solution de continuité que les Caraborda du Bourg voient l'un des leurs membres devenir consul de Toulouse entre 1180 et 1202 133. Le rôle des chevaliers citadins dans la prise des décisions des consuls apparaît même explicitement formulé dans une charte ar-

Mémoires de l'Académie de Vaucluse, 1913, p. 1-42, et, pour une période plus tardive, C. Porée, « Les statuts de la communauté des seigneurs pariers de la Garde-Guérin en Gévaudan (12381313), BEC, 1907, p. 81-129.

128 . $\ll$ Les consulats [...] sont avant tout l'émanation de la chevalerie urbaine : le fait est normal, la ville devient une seigneurie collective autonome au profit de l'aristocratie qui l'babite, elle est l'bomologue du château. », J.-L. Biget, « Les villes du Midi de la France au Moyen Age », dans J.-L. Biget, J.-C. Herve (sous la direction de), Panoramas urbains. Situation de l'histoire des villes, Fontenay, E.N.S. éditions, 1995, p. 159.

129. A. Castaldo, Le consulat, op. cit. (n. 58), p. 57 et R. Limouzin-Lamothe, La commune, op. cit. (n. 55), p. 313. Cf. le partage des droits sur la pêche de l'arrière-pays d'Arles entre les consuls et les moniales de Saint-Césaire, A.D. Bouches-du-Rhône, 60 H $25 n^{\circ} 1$ (24 VI 1178).

130. R. Limouzin-Lamothe, La commune, op. cit. (n. 55), p. 220 et P. Wolff, * Civitas et burgus. L'exemple de Toulouse », dans Regards sur le Midi médiéval, Toulouse, Privat, 1978, p. 207.

131 . A. Dupont, Les cités, op. cit. (n. 5), p. 695.

132. . Les listes consulaires d'Arles et d'Avignon montrent que les premiers consuls sont presque tous, sinon même tous, des chevaliers », J.-P. Poly, La Provence, op. cit. (n. 4), p. 311.

133. J. H. Mundy, Liberty, op. cit. (n. 4), p. 67. 
lésienne de 1142, dans laquelle ces magistrats s'accordent avec l'archevêque au sujet du sel cum saniori parti militum ${ }^{134}$. Véritable oligarchie, la chevalerie urbaine monopolise le pouvoir consulaire dont les plus importantes des attributions sont d'ordre judiciaire et banal.

Dans la conception politique que le Moyen Age hérite de Rome, la justice est indissociable de la paix. Or, le consulat, qui détourne une partie des activités judiciaires de la ville à son profit, naît dans un contexte de pacification. Sa genèse s'inscrit dans le sillon des mouvements de paix de l'an mil. Comme au temps où les guerriers se rassemblaient autour des châsses reliquaires pour jurer de ne plus s'adonner à la violence, les évêques encouragent le consulat, qui leur apparaît comme une association assermentée de milites s'engageant à respecter la paix publique 135. A Avignon, les statuts municipaux s'ouvrent de la façon suivante : "Voici la charte de paix, de concorde et de consulat que moi, Jaufre, évêque d'Avignon, ai dressé avec le conseil et le consentement des consuls» 136 . Toujours dans cette ville, le patronage épiscopal se traduit dans le choix des espaces où la commune chevaleresque manifeste son autorite : les électeurs des consuls sont enfermés dans la cathédrale de Notre-Dame de Doms ; c'est sur son parvis que se tiennent les conseils et les assemblees; le collège consulaire se réunit, sous la présidence de l'évêque, dans son propre palais 137. Le consulat méridional est la dernière manifestation institutionnelle de la paix épiscopale.

Ses membres prêtent un serment qui, dépourvu de toute connotation révolutionnaire, rappelle plutôt celui par lequel, à l'initiative de l'Eglise, les chevaliers juraient jadis de respecter la trêve de Dieu. Le vocabulaire des chartes catalanes en témoigne. En juin 1182, Alphonse Ier (1162-1196) accorde à la ville de Cervera « une confrérie et une unanimité fraternelle », où les habitants choisi ront des consuls parmi les « assermentés de cette confrérie » (conjurati eiusdem confratrie) 138. En 1214, le légat pontifical impose à chacune des villes de Catalogne d'elire deux «paciaires », l'un parmi les « grands» et l'autre dans le

134. F. Kiener, Verfassungsgeschichte der Provence (610-1200), Leipzig, 1900, p. 285 (1142).

135. * La commune d'Avignon [...] est née à l'ombre de la cathédrale, lorsque les lignages chevaleresques de la ville se pensèrent eux-mêmes comme une universitas de paciers, à qui l'évêque déléguait l'administration de la justice et des taxes $»$, J.-P. Poly, « De la citadelle $»$, op. cit. (n. 22), p. 159.

136. Hec est carta pacis et concordie et consulatus quam ego Gauffredus Avinionis episcopus composui, consilio et assensu consulum, Albanès, Chevalier, Gallia, op. cit. (n. 77), t. 7, n⿳2 245 (v. 1129)

137. J.-P. Poly, La Provence, op. cit. (n. 4), p. 312, et M.-L. Labande, Avignon, op. cit. (n. 111), p. 4-5.

138. J.-M. Font Rius, Orfgenes, op. cit. (n. 83), p. 352-356. 
« peuple » avec le conseil de l'évêque 139. Des paciaires apparaissent aussi en Rouergue et Gévaudan. Dans cette région, l'évêque de Mende lève des troupes de chevaliers qui maintiennent la paix sur les routes et empêchent les guerres privées ; ces hommes sont soldés grâce à une taxe, le compensum pacis, dont on conserve les levées dans un coffre gardé dans l'église Saint-Privat 140. Il n'est pas étonnant de retrouver les chevaliers des armées épiscopales, chargées de faire régner l'ordre public, parmi les ancêtres des consuls.

L'iconographie témoigne du lien entre les nouvelles institutions communales et la Paix de Dieu. A l'imitation de l'héraldique aristocratique, les consuls se donnent des emblèmes qui, dans les sceaux et les bannières, manifestent la seigneurie collective qu'ils exercent sur la ville. Dans nos régions, les premiers exemples de cette sigillographie communale datent de la fin du XIIe siecle. A Montpellier, le sceau consulaire est frappé de l'image de la Vierge à l'enfant, symbole éminemment pacifiste 141 : c'est à Notre-Dame des Tables que Pierre II jure de respecter, en 1204, les statuts de cette commune 142. A Toulouse, l'agneau pascal apparaît, pour la première fois, dans un sceau d'avril 1214. Dès février 1219, la Vierge et l'agneau pascal se retrouvent a l'avers et au revers du sceau de Narbonne avec les légendes respectives de «Sceau de paix de Narbonne " et de «Toi qui enlèves les péchés du monde, donne nous la paix »143. La pièce de monnaie frappée par Guillaume IX d'Aquitaine et sa femme Felipa à Toulouse présente l'inscription $P a x$, entouree de Tolosa civi. Par ailleurs, cette ville est quelquefois appelée salvetat, « sauveté » désignant un espace d'asile protégé par la trêve de Dieu à l'intérieur duquel toute violence est

139. singulis civitatibus cives et populi cum consilio diocesani episcopi duos ex se paciarios eligant, unum scilicet de majoribus et alterum de populo, ibid, p. 320.

140. R. Michel, L'administration, op. cit . (n. 29), p. 112, et C. Poré, Etudes historiques sur le Gevaudan, Mende, 1919, p. 363-368. En Catalogne, le bovaticum ou bovatge, taxe * pour les bceufs *, alors qu'on sait les troupeaux l'objet de predilection de la rapine des guerriers, apparaît comme l'équivalent du compensum pacis ; l'assiette de cette taxe est établie, devant le roi, dans les * assemblees de paix et treve ", T. N. Bisson, Fiscal accounts of Catalonia under the early count-kings (1151-1213), Berkeley-Los Angeles, University of California Press, 1984, p. 85-86.

141. En 1183, les encapuchonnés du Puy brodent une image de Notre-Dame sur leur bannière, entourée de la légende « Agneau de Dieu, qui enlèves les péchés du monde, donne-nous la paix », et animent un campagne de pacification qui impose une trêve entre Alphonse Ier de Barcelone et Raimond V de Toulouse, Rigord, Gesta Philippi Augusti, ed. H.-F. Delaborde, Euvres de Rigord et de Guillaume le Breton, Paris, 1882, p. 34-40, $\mathrm{n}^{\circ} 25$.

142. H. Vidal, « Aux temps des Guilhems (985-1204)», dans G. Cholvy (sous la direction de), Histoire de Montpellier, Toulouse, Privat, 1984, p. 27.

143. In n'empêche que d'autres consulats ont des emblèmes ouvertement bellicistes. Dans la bulle d'Arles, le lion est entouré de la devise « On dit habituellement que la colère du lion est la plus noble entre toutes $»$; à l'avers, la ville, puissamment fortifiée, porte la légende * La ville d'Arles est ennemie et épée pour ses ennemis », B. Bedos, Les sceaux des villes, Paris, Archives nationales, 1980, $\mathrm{n}^{\circ} 454$ (1218), 685 (IV 1214), 491 (II 1219) et 44 (1203). 
punie d'excommunication 144. La Paix est, somme toute, inherente à la nature même du consulat.

Elle n'est pourtant pas longtemps respectee. L'un des buts du consulat était, en effet, d'éviter les luttes qui opposaient les chevaliers d'une ville entre eux ; ces guerres avaient souvent pour origine le conflit entre l'évêque et le comte, c'est-à-dire entre les seigneuries laïque et ecclésiastique. A d'autres occasions, elles étaient dues à la concurrence entre deux quartiers, le plus souvent entre la cité romaine et les faubourgs plus récents. A Arles, des révoltes contre l'archevêque sont attestées vers 1150-1156 et en 1191 ; elles coïncident avec les luttes entre la Cité et le Vieux-Bourg pour le contrôle du Méjan, querelles qui recoupent, à leur tour, la guerre privée des Porcelet contre les Baux, coseigneurs de cette ville 145. Autour de 1200, les luttes de la Cité, peuplé par un patriciat ancien de rentiers, contre le Bourg, dominé par des hommes nouveaux enrichis dans le commerce et les affaires, revêtent une acuité particulière à Toulouse. A en croire le chroniqueur Guillaume de Puylaurens, la confrérie blanche - encou ragée par l'évêque Folquet de Marseille pour anéantir l'hérésie et l'usure - recrute surtout dans le premier de ces quartiers, tandis que la confrérie noire est bien implantée dans le Bourg ; les chevaliers se combattent sous l'une ou l'autre bannière 146. Un conflit similaire de quartiers, regroupant des hommes d'origines et d'occupations diverses, existe à Nîmes où les chevaliers des Arènes sont en guerre contre les bourgeois de la Cité depuis le début du XIIe siècle 147. C'est en fonction des affinités topographiques, de l'appartenance à une seigneurie et des origines sociales que se font et defont les partis urbains. Ces factions se combattent impitoyablement. Le consulat échoue, en définitive, dans la pacification de villes dominées par une chevalerie avide de combats.

\section{Spiritualité : religiosité et fin'amors}

Un panorama complet sur les chevaliers citadins ne saurait négliger leur dimension spirituelle et intellectuelle. La présence des milites est particulièrement

144. J. H. Mundy, Liberty, op. cit. (n. 4), p. 26-28.

145. M. Aurell, Une famille, op. cit. (n. 39), p. 91-96.

146. Ex hoc magna inter Cives et Burgenses divisio, ita quod in burgo adversus istam fecenunt aliam confratriam vallatam vinculo juramenti. Tamque processum erat, quod ista dicentur confratria candida, illa nigra, fiebantque cum armis et vexillis, frequenter et equis armatis prelia inter partes. Venerat enim Dominus per ipsum episcopum servum suum non pacem malam sed gladium bonum mittere inter eos, Guillaume de Puylaurens, Chronique, op. cit. (n. 28), p. 64-67,

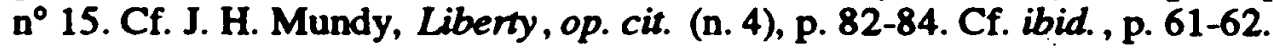

147. MCXXX, obsessum est castrum Arenarum; MCLXVI, concordia militum et burgensium Nemausensium facta est, chronique de Nîmes, édité dans HGL, t. 5, $n^{\circ}$ 5.Cf. A. Dupont, Les cités, op. cit. (n. 5), p. 715. Ideo ut pax et concordia reformetur antiqua inter milites et cives et omnium preteritarum injuriam et delictorum memoria deleatur, L. Ménard, Histoire civile, op. cir. (n. 18), t. 1, PJ 24, p. 45, col. 2 (27 VII 1207). Cf. R. Michel, L'administration, op. cit . (n. 29), p. 204 
frappante dans le chapitre cathédral de leur ville. Nombre de leurs fils y sont offerts a l'Eglise dès leur enfance, en attendant que se libère la prébende qu'ils occuperont adultes ; certains d'entre eux décident d'intégrer la communauté capitulaire dans leur maturité ou dans leur vieillesse 148 . Sans doute sont-ils attirés, au XI e siècle, par la religiosité accrue des chanoines, que la réforme grégorienne a rappelés à leurs devoirs dans le chœur. De nouveaux chantiers voient le jour ; on y reconstruit les cathédrales selon les normes de l'art roman. Ces églises épiscopales sont désormais flanquées de cloîtres qui reconstituent une atmosphère quasi monastique pour les chanoines ; elles traduisent, dans le paysage urbain, l'influence que l'évêque et son entourage canonial exercent sur les laïcs. La cathédrale et ses tours reflètent incidemment la portée de la seigneurie épiscopale sur la ville.

Quelques chiffres permettent de cerner le poids des chevaliers dans le chapitre. Entre le XIe et le début du XIIIe siècle, sur les soixante-cinq chanoines identifiés à Agde, soixante-deux appartiennent à des familles de la cité ou de son arrière-pays : ils « figurent au milieu de leurs parents et alliés, dans les actes, et côte à côte avec les milites portant leur nom 149 ». Tel est le cas de Guilhem Anatole, chanoine entre 1187 et 1208, issu d'une famille qui donne de nombreux consuls à sa ville ou bien de Peire Carbonnel (1153-1183) qui provient d'un important lignage apparenté aux Popian. La même composition chevaleresque se retrouve dans le chapitre de Barcelone 150. A Saint-Nazaire de Béziers, parmi bien des chanoines d'origine aristocratique, figurent Bernard (1092) et Raimond Sigar (1084-1107) : déjà en 969, Sogerius, l'un de leurs ancêtres, apparaît dans l'entourage du vicomte ; les membres de sa famille, qui sont mentionnés en tant que nobiles dans les chartes, realisent des mariages hypergamiques avec les Sauvian, les Pouget et les Puisserguier 151. Le chapitre cathedral est en parfaite osmose avec les familles de la chevalerie.

Sous la conduite de l'écolâtre, les chanoines mènent des études poussées. Au cours de la seconde moitié du XIIe siècle, le droit, aussi bien canon que civil, semble leur science de prédilection : Osbert le Lombard, Rogerius ou Placentin, arrivés du nord de l'Italie, les initient à la lecture du code de Justinien, dont une traduction provençale (Lo codi) est élaborée dans le pays d'Arles vers 1150152.

148. A. Castaldo, L'Eglise, op. cit. (n. 31), p. 21-22.

149. Ibid. p. 19.

150. « The canons rarely admitted wealthy burghers into their ranks, S. Bensch, Barcelona, op. cit. (n. 4), p. 53.

151. C. Duhamel-Amado, La famille, op. cit. (n. 34), t. 2, p. 20-27. Autre exemple du lien familial entre les chevaliers et les chanoines : le frère du sacriste de Lodève détient le tonlieu de la boucherie, E. Martin, Cartulaire de la ville de Lodeve, Montpellier, 1900, $\mathrm{n}^{\circ} 16$ (1108).

152. A. Gouron, La science du droit dans le midi de la France au Moyen Age, Londres, Variorum, 1984. 
Les compilations de lois circulent dans le milieu canonial : le testament de Guilhem Arnaud ( $†$ 1179), sacriste de Saint-Paul de Narbonne, mentionne ses « livres de lois, à savoir le vieux et le nouveau Digeste, les Institutes et le Décret $» 153$. Les chapitres deviennent une véritable pepinière de légistes : leurs membres sont nombreux à être mentionnés dans les chartes avec le titre de « maître ès lois » (magister) ou d' « avocat » (causidicus).

Leur savoir juridique leur ouvre des carrières brillantes. Nicolas Brekspear, ancien chanoine de Saint-Ruf d'Avignon, centre majeur de diffusion du droit romain, devient pape sous le nom d'Adrien IV (1154-1159); le jurisperitus Raimond des Arènes de Nîmes, conseiller de l'ordre de Cîteaux, est nommé cardinal 154. Ces chanoines juristes mettent leurs connaissances au service des princes. Oleguer, archevêque de Tarragone, formé lui aussi à Saint-Ruf, est le bras droit de Raimond Bérenger III de Barcelone. D'ailleurs, la cour comtale de Provence recrute de nombreux légistes dans les chapitres cathedraux : sous Alphonse Ier, Bernard Auriac, doyen, Guilhem Barreira, professeur, et Rainaud de Sainte-Croix, tous trois membres du chapitre d'Arles, ainsi que Peire Audebert, chanoine d'Aix, et Rodolf, chanoine d'Antibes, travaillent dans l'administration du comte, qui tire profit de leurs compétences techniques pour affermir son pouvoir 155. La vieille collusion entre le prince, qui cherche à rétablir la paix au détriment de l'aristocratie châtelaine des campagnes en révolte, et le patriciat urbain, partisan d'un retour à l'ordre au profit de ses affaires, transparait dans les services rendus au comte par des chanoines issus des familles de la chevalerie.

Même si le chapitre cathédral draine une bonne partie des nobles des villes voués à l'Église, la spiritualité du clergé régulier attire parfois la chevalerie urbaine. Cela est notamment le cas pour les ordres militaires, qui connaissent un franc succès sur le pourtour méditerranéen au XII e siècle. Les maisons du Temple et de l'Hôpital sont nombreuses dans les villes de Provence, Languedoc et Catalogne, d'ou partent leurs hommes, leurs chevaux et leurs subsides pour la Terre sainte. L'idéal du moine-guerrier qu'on y prône attire maints chevaliers qui adhèrent à des ordres prenant en compte les aspirations religieuses des combattants. Quelques-uns d'entre eux prononcent leurs voux dans la jeunesse. Ms sont, cependant, plus nombreux à devenir donats : tout en restant dans le siècle, ces laïcs s'engagent à prendre l'habit templier ou hospitalier dans la vieillesse, voire sur le lit de mort. Au cours de la croisade albigeoise, les ordres militaires,

153. Libros de legibus (...) scilicet Digesta nova et vetera et Instituta et Decretos, cité par J. Caille, « Le consulat », op. cit. (n. 77), p. 248.

154. J.-P. Poly, « Les légistes », op. cit. (n. 122), p. 613-635.

155. M. Aurell, * Els fonaments socials de la dominació catalana a Provença sota Alfons el Cast (1166-1196) », Acta Historica Archaeologica Mediaevalia, 5-6 (1984-1985), p. 83-110. 
qui recrutent dans une large frange de la noblesse méridionale, paraissent plutôt favorables au comte de Toulouse et à ses partisans qu'a Simon de Montfort 156.

Il n'en va pas de même avec Cîteaux, mis souvent à contribution pour éradi quer l'hérésie en raison de sa fidélité inébranlable au Saint-Siège 157. Or, les chevaliers des villes semblent peu nombreux a devenir moines cisterciens, contrairement aux nobles des campagnes proches de leurs monasteres 158 . Nombre de leurs filles prennent, en revanche, le voile à Citeaux. L'aristocratie urbaine participe à la renaissance du monachisme féminin qui intervient dès la fin du XII' siecle. En Provence, les Porcelet d'Arles fondent Mollegès, où de nombreux membres de leur famille deviennent abbesses et moniales; les Roquefort, fideles des vicomtes de Marseille, manifestent autant d'enthousiasme pour Notre-Dame de Sion ${ }^{159}$. L'encouragement des formes monastiques de la reli giosité féminine est un trait de la noblesse urbaine : depuis longtemps, les établissements pour femmes se trouvaient, en effet, à l'intérieur des villes où les moniales jouissaient d'une sécurite qu'elles n'auraient pu obtenir en rase campagne. Les chevaliers citadins animent, de même, l'assistance et la charité en milieu urbain par les nombreux hôpitaux, léproseries et hospices qu'ils fondent et entretiennent : ces établissements sont souvent gérés par des laïcs, même si, au XIII siècle, les autorités épiscopales ont tendance à les reprendre en main 160 .

Dans les cites, les relations entre la chevalerie et l'épiscopat ne sont d'ailleurs pas toujours au beau fixe. Au XIe siecle, une partie des guerriers des villes appuie les vicomtes dans le conflit qui les oppose à l'évêque pour le contrôle de la seigneurie urbaine. Des poussées d'anticléricalisme sont encore fréquentes au XIIe siecle 161 ; elles prennent des formes bien plus violentes a l'époque de la croisade albigeoise 162 . En 1202, l'évêque de Lodève voit son palais dévalisé par les habitants de la ville, qui le forcent à prêter serment de fidélité au consu-

156. E. Delaruelle, « Templiers *, op. cit. (n. 68), p. 315-334 ; J. H. Mundy, Liberty, op. cit. (n. 4), p. 17.

157. M.-H. Vicaire, Histoire de saint Dominique, Paris, 1957, t. 1, p. 169.

158. Quelques éléments sur le recrutement d'un grand établissement cistercien, dans $\mathbf{M}$. Mousnier, * Grandselve et la sociéte de son temps », Cahiers de Fanjeaux, 21 (1986), p. 110.

159. M. Aurell, * Les cisterciennes et leurs protecteurs en Provence rhodanienne », ibid., p. 235-268.

160. Cf. Assistance et charite. Cahiers de Fanjeaux, 13 (1978), et D. Le Blévec, Recherches sur l'assistance dans les pays du Bas-Rhone du XII au milieu du XVe siecles, Thèse de doctorat d'Etat inédite, Université de Paris IV, 1994.

161 . J.-P. Poly, La Provence, op. cit. (n. 4), p. 313.

162. J. Chiffoleau, \& I ghibellini nel regno di Arles », Federico II e le cittd italiane, Palerme, Sellerio, 1994, p. 364-398. 
lat ; il est assassiné, en 1211, par seize Lodévois ${ }^{163}$. A l'orée du XIII e siècle, le mouvement communal, qui était né paradoxalement sous la tutelle épiscopale, prend souvent une tournure ouvertement anticléricale.

Aussi virulente soit-elle, la lutte pour l'émancipation de la seigneurie épiscopale ne saurait être confondue avec l'hérésie, rejet délibéré d'une partie du dogme catholique 164 . Elle ne se place pas, a fortiori, sur le même registre que le catharisme, système de croyances coherent où le dualisme coexiste avec un christianisme évangélique 165. La religion des « Bons chrétiens » a son épicentre dans un triangle dont les lignes convergent vers Toulouse, Carcassonne et Albi ; elle ne prend guère en Provence, en Bas-Languedoc ou en Catalogne 166. Au XII ${ }^{e}$ siecle, son recrutement est, presque exclusivement, aristocratique ${ }^{167}$. Une anecdote rapportée par la chronique de Guillaume de Puylaurens corrobore cet élitisme : à l'évêque de Toulouse qui lui demande * Pourquoi ne chassez-vous pas les hérétiques de vos terres ? », un chevalier répond : "Nous ne le pouvons pas. Nous avons été élevés ensemble et nous avons des hommes de notre sang parmi eux 168 ».

Même s'il s'agit d'un phénomène qui se développe surtout dans les castra, villages fortifies, la nouvelle religion ne se diffuse pas moins parmi les chevaliers urbains en délicatesse avec l'épiscopat. Le consul Peire Maurand, dont la famille possede une tour puissante et une maison fortifiee dans le Bourg de Toulouse et des droits seigneuriaux dans son arrière-pays, est présenté par le chroniqueur anglais Roger de Hoveden comme un hérésiarque se faisant passer pour saint Jean l'Evangéliste : il est effectivement condamné pour hérésie vers

163. E. Martin, Cartulaire..., op. cit. (n. 151), p. 33, $\mathrm{n}^{\circ} 34$ (6 VI 1202) et A. Dupont, Les cités, op. cit. (n. 5), p. 710-711.

164. A. Vauchez, \& Un Moyen-Age sans hérésie ? », Heresis, 13-14 (1990), p. $449-456$

165. A. Brenon, Les cathares. Vie et mort d'une Eglise chrétienne, Paris, J. Grancher, 1996.

166. A Béziers, il y a à peine $2 \%$ d'hérétiques au moment du massacre de $1209, \mathrm{H}$. Vidal, Episcopatus et pouvoir, op. cit. (n. 46), p. 74. Pour Agde, A. Castaldo conclut : « puissance ecclesiastique, hérésie inexistante $», L^{\prime} E g$ lise, op. cit. (n. 31), p. 81. Cf. J. Chiffoleau, M. Zerner, « Vie et mort de l'hérésie en Provence et dans la vallée du Rhône du début du XIIIe au début du XIVe siecle \#, Cahiers de Fanjeaux, 20 (1985), p. 73-99. Ne confondons pas, non plus, le camp de Raimond VI et de Pierre II lors de la croisade avec celui des ardents défenseurs des hérétiques, point de vue démenti, entre autres, par la lettre envoyée par les consuls de Toulouse au comte de Barcelone : multos [hereticos] combussimus et adhuc cum invenimus idem facere non cessamus, HGL, t. 7, col. 614, $\mathrm{n}^{\circ} 161$ (1211).

167. * Aristocratique de naissance, le catharisme occitan se popularisa profondément , Brenon, Les cathares, op. cit., p. 242. J.-L. Biget n' accepte pas cette démocratisation du catharisme qu'il réserve aux seules élites : cf. * Cathares », op. cit. (n. 37), p. 301-305, et son échange avec A. Brenon dans Hérésis, 24 (1995), p. 91-100.

168. Guillaume de Puylaurens, Chronique, op. cit. (n. 28), p. 48-51, ch. 8, cité par C. Amado, * Faible impact de l'hérésie dans le Languedoc central méditerranéen. Le paradoxe biterrois (1170-1209) », dans Europe et Occitanie. op. cit. (n. 37), p. 83-103. 
1180 169. Les élites urbaines de Toulouse sont sensibles aux prêches des Parfaits. Dans les villes de cette région, la chevalerie connaît le catharisme, auquel elle adhère parfois.

De même que sa religiosité présente des manifestations spécifiques, la culture profane de la chevalerie d'Occitanie est originale à bien des égards. Au XIIe siècle, les connaissances livresques que diffusent les écoles capitulaires arrivent jusqu'à ses palais. Tandis que s'elève le niveau d'instruction des sires citadins, le gout du luxe venu de l'Orient se répand dans leurs maisons fortes. Les marchands leur apportent les esclaves sarrasins, musiciens et chanteurs, ainsi que les objets prestigieux qu'ils ont vus au cours des croisades ou des pelerinages les ayant menes dans le monde arabe. Savoir et raffinement cohabitent dans ces cours, seigneuriales et urbaines a la fois, qui deviennent la demeure privilégié des troubadours, l'atelier de création de leur poésie et le centre de diffusion de leurs chansons. Cette culture originale, qui permet l'épanouissement de l'art troubadouresque, est à la fois courtisane ou courtoise.

Les palais des princes méridionaux attirent de nombreux troubadours. Les cours des comtes de Toulouse et de Barcelone, mais aussi des vicomtes de Marseille ou des seigneurs de Montpellier, sont particulièrement brillantes à la fin du XIIe siècle. Parmi les poètes qui les frequentent figurent de nombreux chevaliers citadins : la vida, biographie précédant dans les manuscrits une chanson, de Guiraudet le Roux nous apprend, par exemple, qu'il « fut de Toulouse, fils d'un pauvre chevalier » ; celle de Ricau affirme que «c'était un chevalier de Provence, originaire de la ville fortifice de Tarascon ». On trouve aussi des trobairitz, poétesses, parmi ceux qui composent des chansons en langue d'oc, comme Azalaiis de Porcairagues, dame de Montpellier 170. Les thèmes amoureux que diffusent les troubadours frappent tout particulièrement la sensibilité des milites. Pour conquérir la dame, une soumission absolue lui est requise. Cette obeissance est exprimée dans les métaphores du code féodal. Elle ne va pas sans rappeler la dépendance que chaque chevalier doit à son seigneur. La fin'amors répond, d'ailleurs, au même processus d'intériorisation de normes sociales qu'on retrouve dans les Ensenhamens, ancêtres des manuels de civilité, qui précisent le comportement que chacun doit adopter à la cour 171. A la fin du XIIe siecle, les palais des villes deviennent un lieu d' « urbanite », où les chevaliers empruntent des manières manifestant leur distinction.

169. J. H. Mundy, Liberty, op. cit. (n. 4), p. 10, 60-61, 228 et 270-271. Cet auteur présente, peut-être de façon un peu schématique, une vieille aristocratie toulousaine attachée à l'évêque en opposition avec les nouveaux riches, implantés surtout au Bourg, que l'indulgence des cathares pour le commerce, les affaires et le prêt à intérêt gagne à l'hérésie, ibid., p. 78.

170. J. Boutière, A.-H. Schutz, I.-M. Cluzel, Biographies des troubadours, Paris, 1964, p. $341-342, \mathrm{n}^{\circ} 52$, p. $345-346, \mathrm{n}^{\circ} 54$ et p. $513, \mathrm{n}^{\circ} 86$.

171 . G. Sansone, Testi didattico-cortesi di Provenza, Bari, Adriatica, 1977. 
Aussi courtois que militaires, les chevaliers citadins d'Occitanie adhèrent à une culture spécifique ${ }^{172}$. Ils aiment la guerre et chantent la vaillance, la rapine et la largesse dans leurs compositions de troubadours; ils ne dédaignent pas l'amour courtois, sublimant leur passion pour la dame dans des termes épurés. Leurs connaissances juridiques les poussent à gouverner la ville dans le cadre du consulat, dont le vocabulaire et les institutions s'inspirent largement du code de Justinien. Leur spiritualite est marquee par les chanoines, souvent leurs parents, dont les chapitres sont réformés autour de l'an mil ; elle s'inspire largement des Templiers et des Hospitaliers, qui proposent un idéal de vie adapté a leurs activités militaires. Mais leur contestation de la seigneurie épiscopale peut les mener parfois vers l'anticléricalisme, voire vers l'hérésie. Au XIIe siècle, la mentalité de ces combattants n'est pas insensible aux raffinements de la courtoisie ni aux exigences du monachisme ou du catharisme.

La domination des chevaliers sur les cités occitanes ne peut résister indéfiniment aux transformations sociales. Au XIIIe siecle, une partie du pouvoir sur les villes leur échappe. A l'époque, leurs lignages sont divisés en plusieurs branches collatérales ; cet éclatement pousse bien des cadets à quitter la cité et ses garnisons pour s'installer a la campagne où ils construisent leurs maisons fortes. Ce phénomène est aisément observable à Barcelone où, dès 1140, nombreux milites commencent a abandonner leur ville après avoir fait donation de leurs biens urbains a la cathédrale 173. A partir de 1170, les Maureilhan hypothequent, au chapitre Saint-Nazaire, leurs droits sur le Bourg épiscopal de Béziers qu'ils perdent vers 1240 ; l'essentiel de leurs biens se trouve désormais dans leur castrum patronymique 174. Plusieurs familles de guerriers perdent ainsi leurs attaches urbaines.

Cette désertion s'explique, en partie, parce que les chevaliers ont pressenti la perte de leur puissance et de leur influence politiques. Depuis les annees 1150, 1'Occitanie connaît, en effet, un démarrage commercial sans précédents. Une classe marchande et artisanale, dotée d'une conscience propre, se constitue alors. Ses membres sont trop nombreux pour être intégrés et assimilés, comme par le passé, dans la chevalerie. Ils accedent, en revanche, massivement aux instances consulaires vers 1200 : en 1202, ces nouveaux riches deviennent majoritaires parmi les capitulaires de Toulouse 175 ; en 1204, la révolte de Montpellier, fomenté certes par un parti où les chevaliers sont bel et bien actifs, mène au

172. « Occitania was not a chivalric society, but it was a courtly society », L. M. Paterson, The World, op. cit. (n. 67), p. 90. Cette assertion est sans doute excessive, meme si elle se fonde, entre autres, sur l'absence de tournois dans le Midi du XII e siècle, contrairement au nord de la France, où ils représentent une forme de prédilection de la sociabilité nobiliaire.

173. S. Bensch, Barcelona, op. cit. (n. 4), p. 135-136, 147-149 et 172-173.

174. C. Duhamel-Amado, La famille, op. cit. (n. 34), t. 2, p. 472-480.

175. P. Wolff, « L'essor $»$, op. cit. (. 79), p. 85. 
pouvoir de nombreux bourgeois 176. En Provence, les chefs des métiers sont de plus en plus représentés à la tête de la commune : ils pénètrent dans le conseil en 1218 a Marseille, en 1225 à Avignon et en 1247 à Arles 177. A l'époque, les milices communales constituent un contado autour des villes, empêchant les châtelains de lever leurs péages et d'exercer leurs pillages sur les marchandises échangées dans leur cité 178.

L'affirmation du pouvoir royal coïncide avec cette montée des spécialistes du commerce, de la finance et de la manufacture. L'administration princière $s$ 'affirme nettement sur les communes urbaines au lendemain de la croisade albigeoise en Languedoc, après l'avènement de Charles d'Anjou en Provence et au cours du long règne de Jacques Ier en Catalogne. Un ordre nouveau s'instaure ainsi, dans lequel la guerre n'est plus l'apanage des seigneurs urbains, mais du roi seul. En 1226, Louis VIII remporte les dernières batailles de la croisade, démantelant les maisons fortes d'Avignon et expulsant les milites des Arènes de Nîmes 179 . Le paysage urbain et l'organisation du pouvoir municipal s'en trouvent bouleversés.

Ces transformations ont la force d'un symbole. Elles traduisent la fin de la société urbaine organisée pour la guerre. La ville cesse d'être forteresse, citadelle imprenable ou repaire de gens d'armes. Elle devient, par contraste, marché. Le milieu des affaires la contrôle dorénavant. Il en découle une nouvelle identité civique, imprégnée davantage de valeurs bourgeoises que d'éthique chevaleresque. Les modèles de comportement hérités de la noblesse militaire de l'an mil ne s'effacent pourtant pas d'un trait ; ils marquent a jamais les mentali tés des élites citadines d'Occitanie.

176. H. Vidal, « L'Aragon et la révolution montpelliéraine de 1204 », Montpellier, la couronne d'A ragon et les pays de langue d'oc (1204-1349), Montpellier, Société archéologique, 1987, t. 1, p. 43-60.

177. V.-L. Bourrilly, Essai, op. cit. (n. 31), p. 26.

178. J. H. Mundy, Liberty, op. cit. (n. 4), p. 68.

179. Ci-dessus notes 29 et 30. 


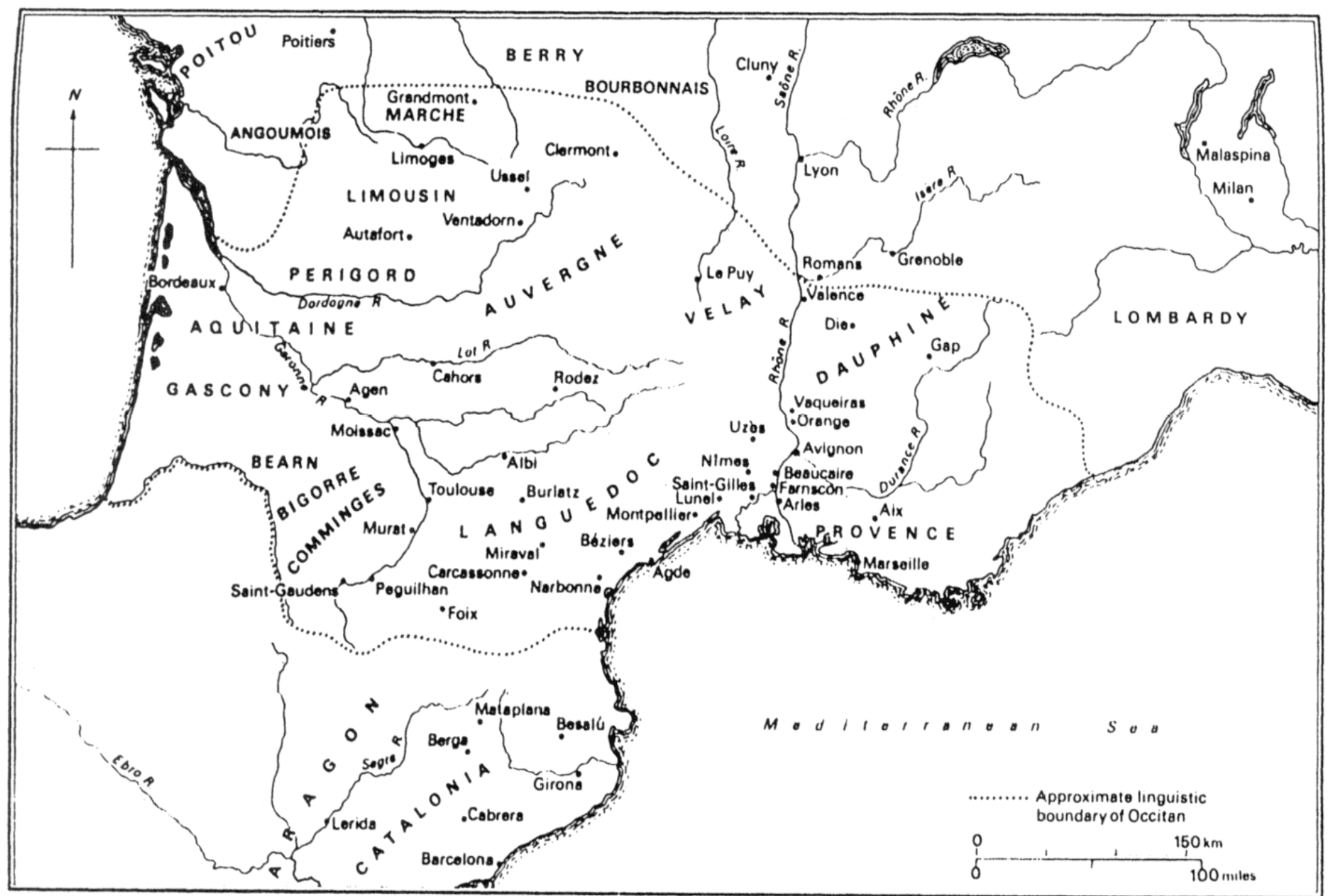

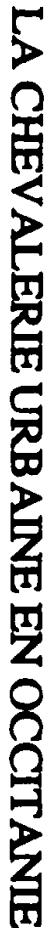

Figure 1

L'espace occitan et ses principales villes. Extrait de L. M. Paterson, The World of the Troubadours. Medieval Occitan society, c. 1100-c. 1300, Cambridge, University Press, 1993, p. XIII. 


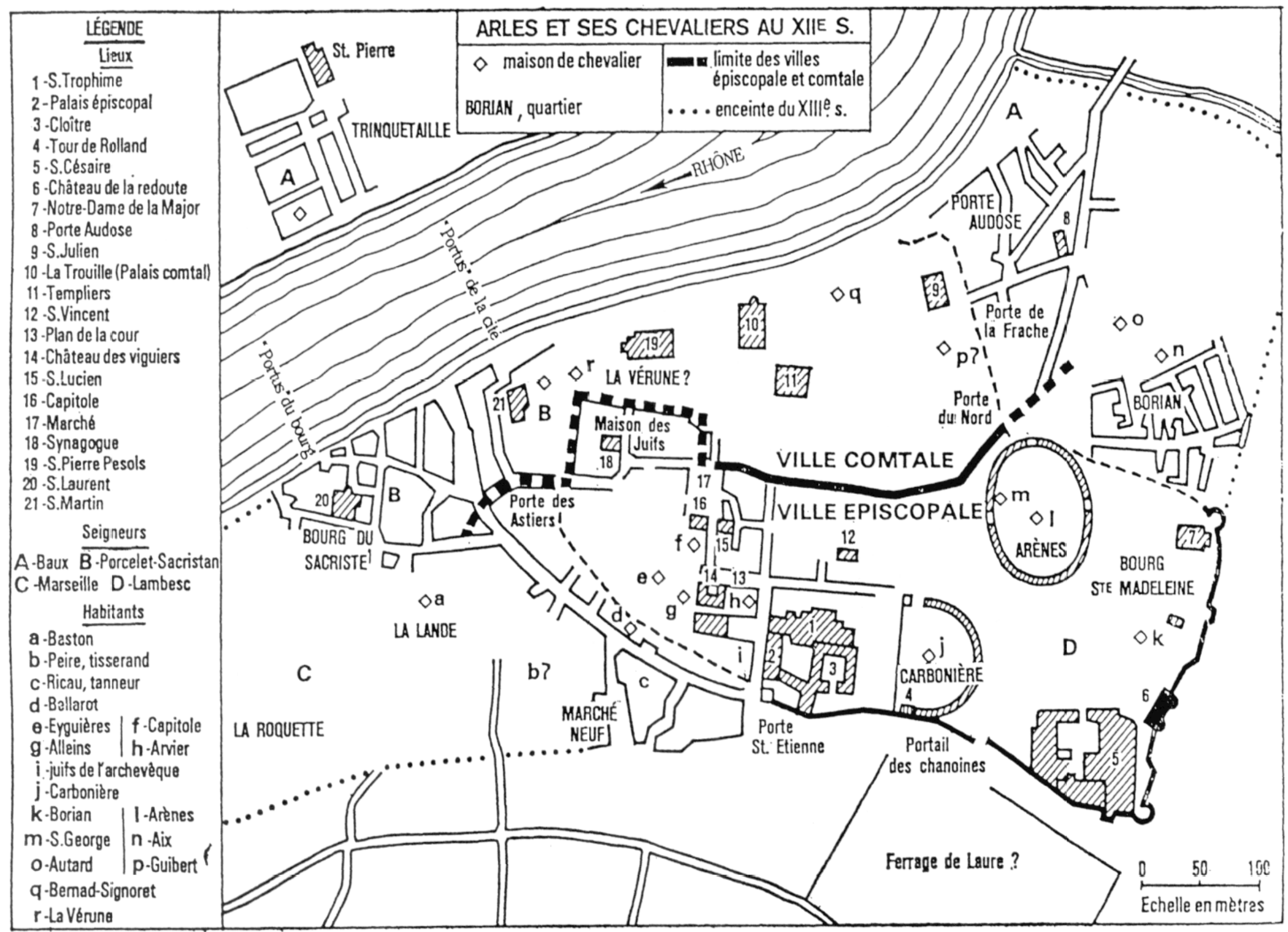

Figure 2

Arles et ses chevaliers au XIII siècle. Extrait de J.-P. Poly, La Provence et la société féodale (879-1166), Paris, Bordas, 1976, p. 294. 


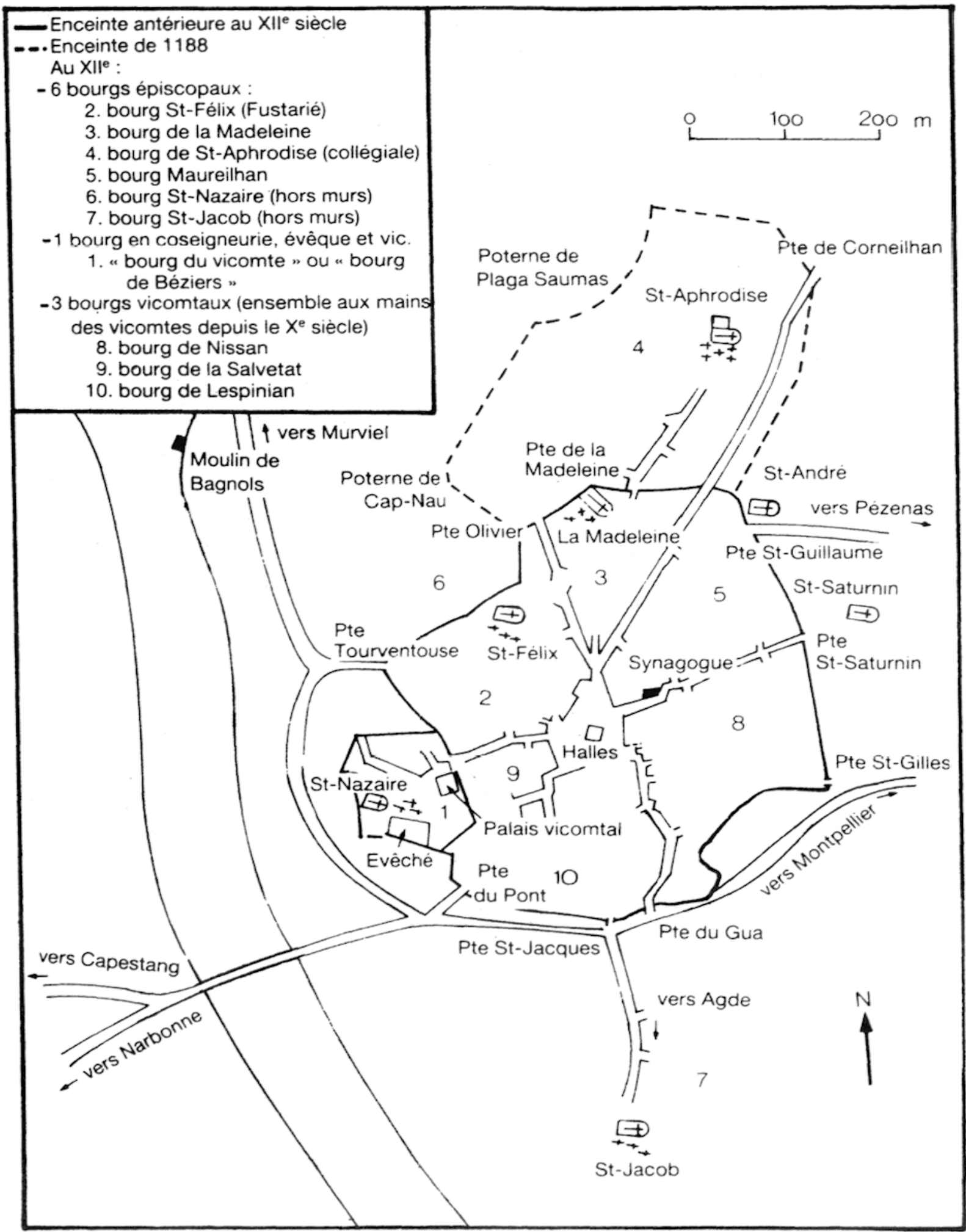

Figure 3 - Béziers au XII e siècle. Plan réalisé d'après le tracé d'Y. Esquieu, publié dans Histoire de Béziers, Toulouse, Privat, 1986, p. 83. 


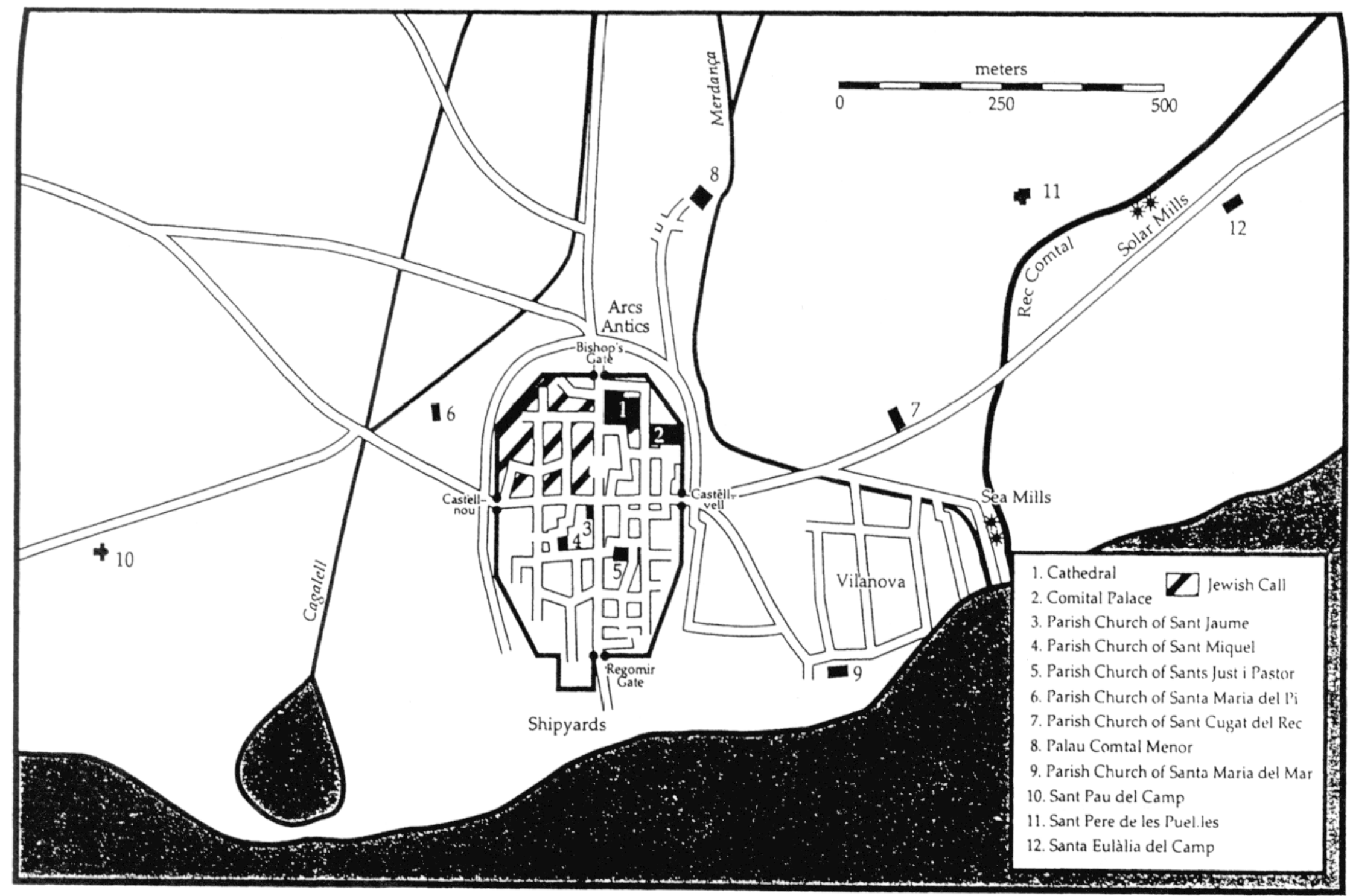

Figure 4

Barcelone en 1100. Extrait de S. Bensch, Barcelone and its rulers, 1096-1291, Cambridge, University Press, 1995, p. 89. 


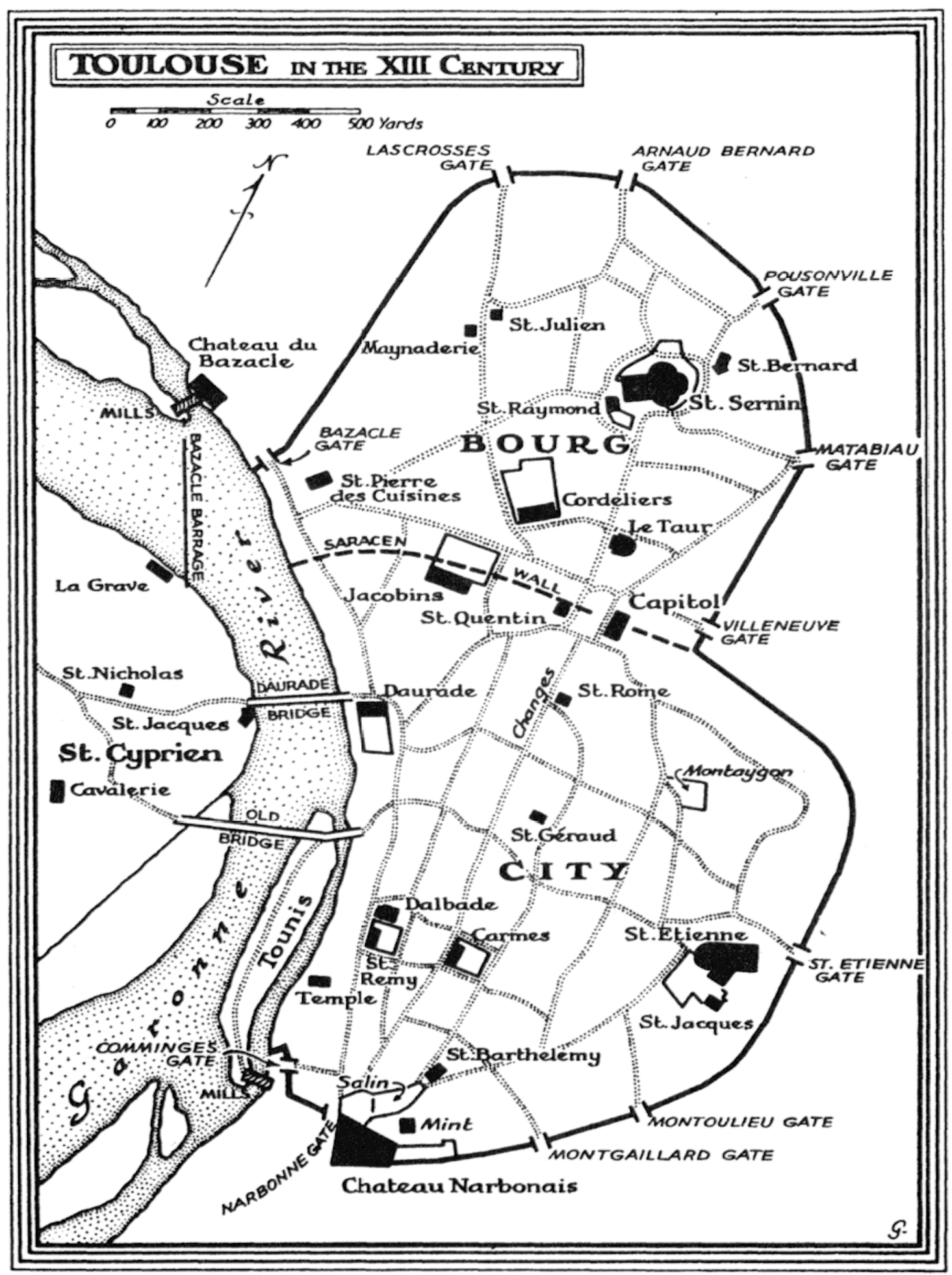

Figure 5 - Toulouse au XIIIe siecle. Extrait de J. H. Mundy, Liberty and Political Power in Toulouse, 1050-1230, New York, 1954, p. 6. 


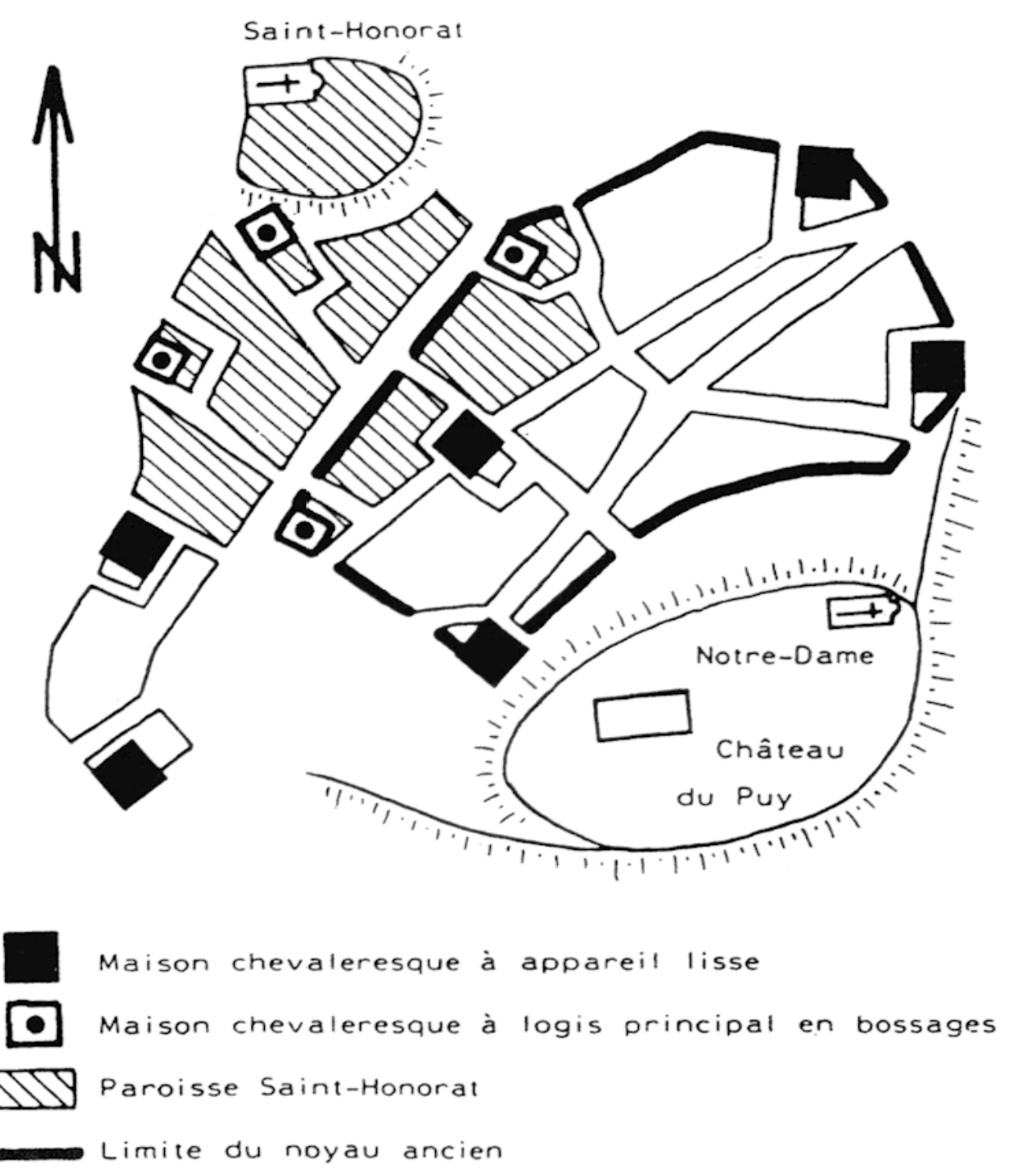

Figure 6 - Grasse vers 1200. Extrait de D. Ferre, J.-C. Poteur, « Les demeures nobiliaires dans les consulats aristocratiques (Grasse, Cruas, SaintMarcel d'Ardèche) », dans Le village. Actes des journées d'histoire régionale de Mouans-Sartoux (16-17 mars 1984), Mouans-Sartoux, 1984, p. 82. 


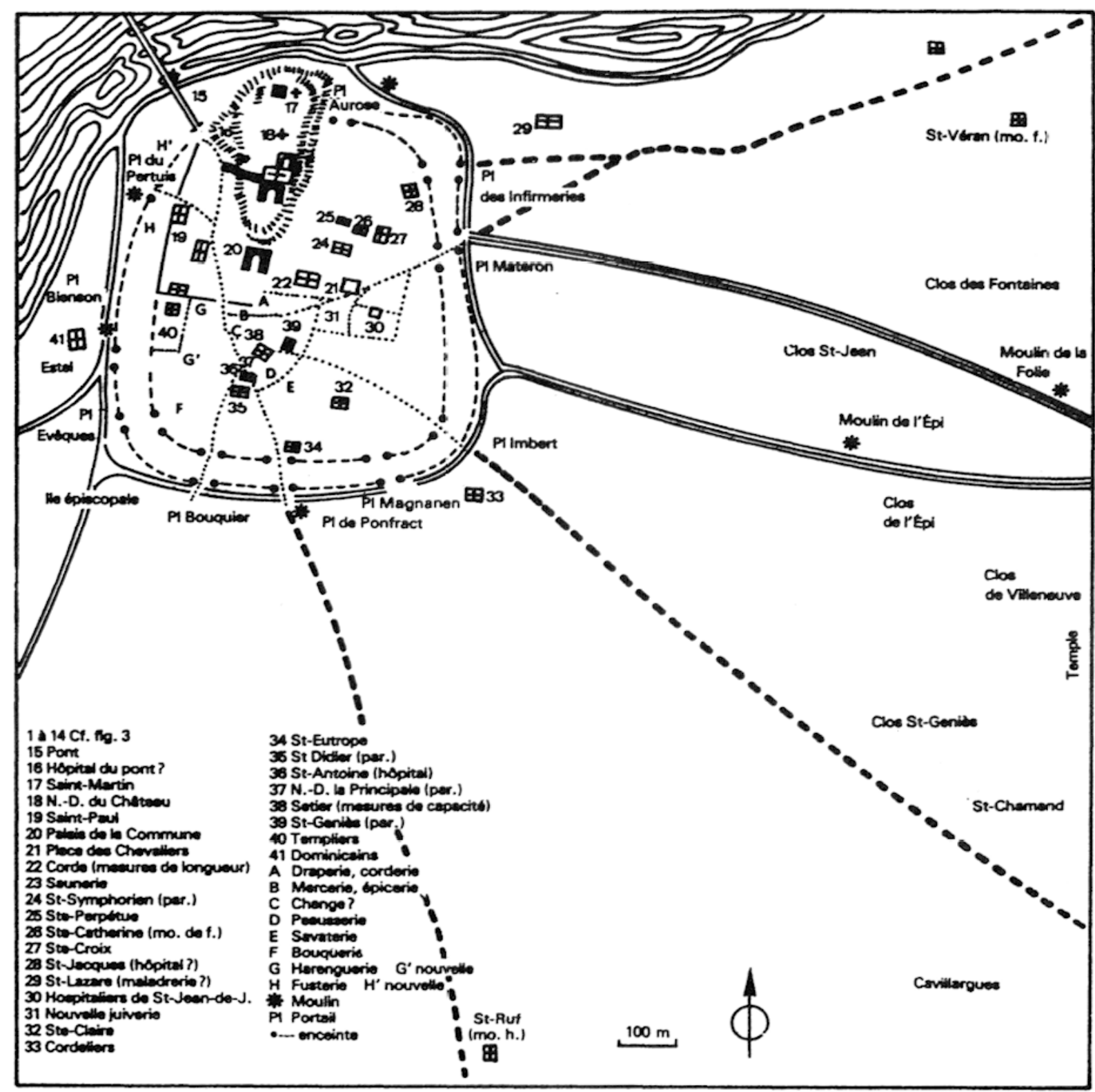

Figure 7 - Avignon au XIIIe siecle. Extrait de J.-P. Poly, « De la citadelle du fleuve a la capitale de la chrétienté (VIIe-XIVe siècles)», dans Histoire d'Avignon, Aix, Edisud, 1979, p. 145. 


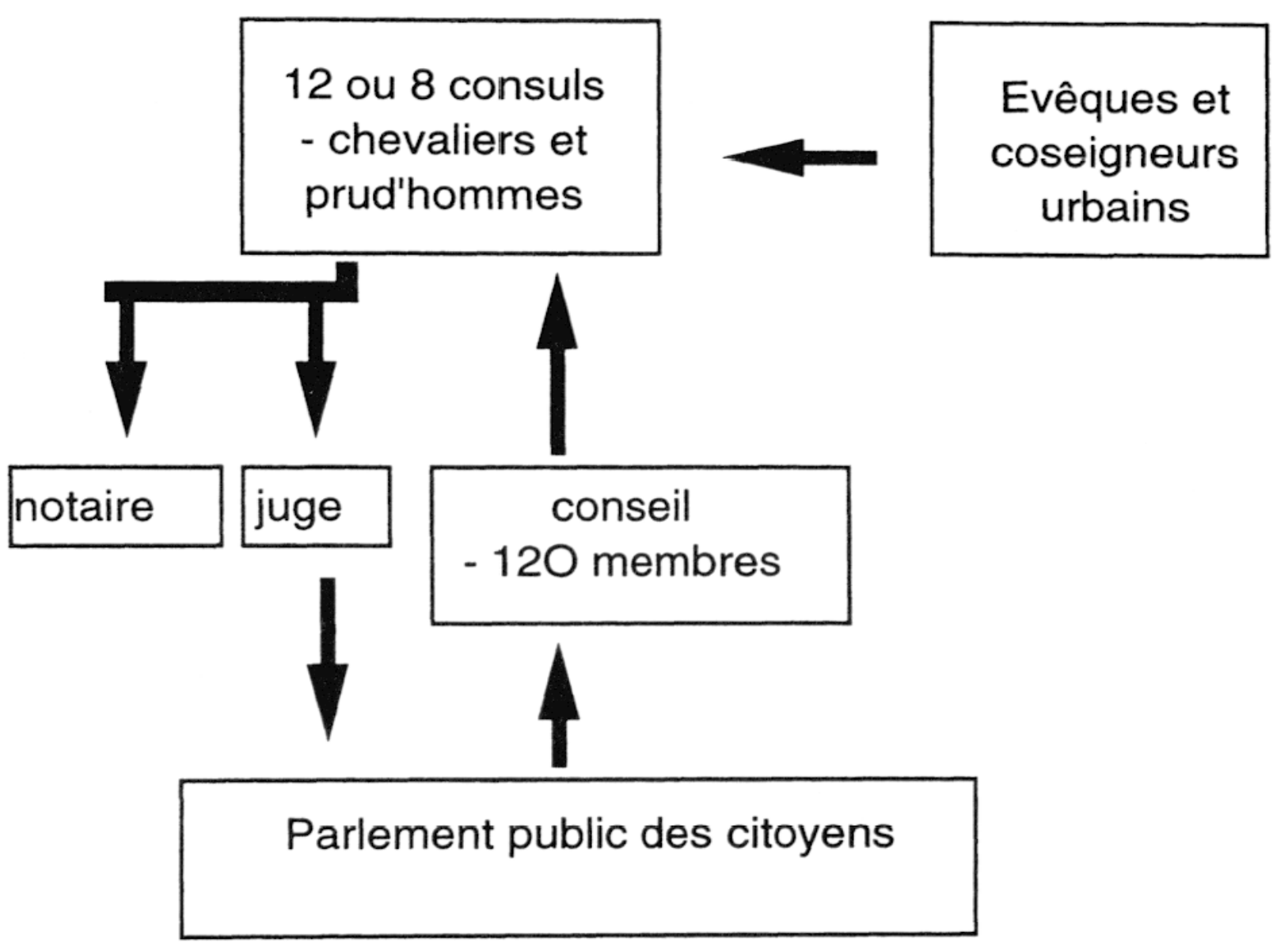

Figure 8 - Les institutions consulaires 